\title{
Instability and the Incentives for Corruption
}

Filipe R. Campante, Davin Chor, and Quoc-Anh Do

CID Graduate Student and Postdoctoral Fellow

Working Paper No. 6, March 2005

(c) Copyright 2005 Filipe R. Campante, Davin Chor, Quoc-Anh Do, and the President and Fellows of Harvard College at Harvard University 


\title{
Instability and the Incentives for Corruption*
}

\author{
Filipe R. Campante, Davin Chor and Quoc-Anh Do ${ }^{\dagger}$ \\ Harvard University
}

March 4, 2005

\begin{abstract}
We investigate the relationship between corruption and political stability, understood as the likelihood of the incumbent being able to implement his preferred policies over time. We propose a model driven by two effects: The horizon effect, according to which more instability leads the incumbent to be more corrupt during his short window of opportunity; and the demand effect, by which the private sector is more willing to bribe more stable incumbents. The former effect dominates for low values of stability, since firms are unwilling to pay high bribes, but the latter effect prevails in highly stable regimes. This U-shaped pattern is confirmed by the cross-country evidence as well as several case studies: Countries or political regimes with very high or very low levels of stability display higher corruption, when compared to those in an intermediate range of stability. We also find evidence that corruption is U-shaped with respect to the size of government, confirming one of the corollaries of our model.
\end{abstract}

Keywords: Corruption, Political Stability, Size of Government JEL Classification: D72, E62, K4, O11.

${ }^{*}$ We thank Philippe Aghion, Alberto Alesina and Andrei Shleifer for their helpful comments. Thanks also to Beatriz Armendariz, Abhijit Banerjee, Michael Kremer, David Laibson, James Robinson, as well as seminar participants at Harvard. Chor thanks the Singapore Management University (SMU) for hosting him during the summer of 2004. All remaining errors are ours.

$\dagger$ Department of Economics, Harvard University. Littauer Center, Room 200, Cambridge, MA 02138, USA. Email: campante@fas.harvard.edu; chor@fas.harvard.edu; do@fas.harvard.edu. 


\section{Introduction}

This paper investigates how political stability, broadly defined, affects the incentives to engage in corrupt behavior. By political stability, we refer to the probability that the incumbent public official can successfully implement his favored projects or policies over time. For example, high-value projects such as the exploitation of a natural resource or a lucrative construction contract often take time to generate their full monetary returns, and can thus be stopped before completion if the incumbent is removed from power or if the opposition has sufficient clout to block the project. In this context, stability is linked to the security of tenure of the incumbent, but it is not confined to this: What we have in mind can be termed more generally as "policy stability". It is worth stressing that we do not limit this definition to the violent or unconstitutional removal of the incumbent, as is often the connotation of the term "political instability". ${ }^{1}$

We start from the premise that corruption can take two different forms: (i) Embezzlement, defined as the direct stealing of government property for personal gain, and (ii) Licensing, understood as the transfer of government property to a third party in exchange for a bribe. ${ }^{2}$ We propose a model that takes into account the effects of political stability on the incentives for these two distinct kinds of corruption. On the one hand, a lower level of stability shortens the incumbent's effective decision-making horizon, making him more corruptible: A less stable incumbent finds it optimal to steal more today, given the uncertainty over whether he will still be in power or whether his policy decisions will still be implemented in the next period. This horizon effect can be characterized as a "supply"driven effect, as it has to do with the increased willingness of the public official to "supply" opportunities for corruption. ${ }^{3}$

\footnotetext{
${ }^{1}$ For convenience, we will sometimes lapse into referring to stability as the probability of staying in power. The broader interpretation of stability should nevertheless be kept in mind especially in the empirical section, as the measures we use capture elements of the more general notion of "policy stability".

${ }^{2}$ Glaeser and Goldin (2004) adopt a similar characterization of the different ways in which corruption manifests itself.

${ }^{3}$ Note that this effect will be mitigated if there is a possibility that the incumbent can return to power some time after being ousted. Such an occurrence will presumably be likelier when there is more turnover and instability in the political environment. In a companion paper (Campante, Chor and Do [2004]), we show using an infinite-horizon Bellman approach that this "resurrection" effect dampens the horizon effect, but does not reverse it.
} 
On the other hand, corruption often entails a long-term relationship between the incumbent and a private firm, such as when it is based on the provision of a resource concession that will take several periods to fully exploit. In this situation, the private sector's willingness to pay bribes actually increases with political stability, as businesses will be more inclined to wheel-and-deal with an incumbent whose position they are confident is secure. More generally, a stable regime is more conducive for an incumbent and the private sector to develop the connections through which the flow of bribes will run. This effect being driven by the private sector's demand for corruption, we dub it the demand effect, for lack of imagination. ${ }^{4}$

We present a model in Section 2 in which a self-interested incumbent makes an optimal trade-off (from his perspective) between these two forms of corruption. However, there is a possibility in every period that the incumbent will be ousted or that his policies will be blocked. We show that when stability is low, the horizon effect dominates, as the private sector is reluctant to offer too much in bribes, and direct stealing will be the main source of corruption revenues. In this case, corruption falls when stability improves. However, when stability is high, the demand effect is stronger, since the prospect of long-term deals raises the private sector's demand for corruption. As a result, corruption now increases with stability. Bringing these two effects together, our theory predicts a U-shaped relationship between corruption and political stability. ${ }^{5}$ This pattern holds both in the basic case where stability is treated as exogenous, as well as in an extension where the incumbent can boost his stability through the provision of public goods.

The picture presented in our model is consistent with a lot of anecdotal evidence. On one end of the spectrum, countries such as Brazil (in the early 1990s) and Pakistan have grappled with a combination of low stability and high corruption. For example, Easterly

\footnotetext{
${ }^{4}$ The idea of modelling corruption as the outcome of demand and supply forces within an unofficial market is not new, with Shleifer and Vishny (1993) being a seminal piece in this literature. Along these lines, Dick (2001) has argued that corruption in Indonesia should be analyzed through the framework of a market for public sector services that have been kept at a level of "artificial scarcity". One contribution of our paper is to analyze how political instability interacts with these demand-supply effects to influence the level of corruption.

${ }^{5}$ It is interesting to note that in one of the first cross-country empirical studies on corruption, Mauro (1995) reported a positive correlation between the Business International corruption index for 1980-1983 and a subjective index of political stability from the same source. However, Mauro did not explore the possibility of a non-monotonic relationship.
} 
(2003) surmises that "political instability has made Pakistan's successive governments more like Mancur Olson's (2000) 'roving bandit', who loots only for today" (p. 464). Conversely, autocratic regimes such as Mexico under the Institutional Revolutionary Party (PRI), Kenya under Moi, and Indonesia under Suharto were stable for long periods of time, but saw extensive corruption as the ruling elite exercised a monopoly over rent-seeking activities. Last but not least, competitive democracies with regular elections fall conveniently in the category of intermediate stability and lower levels of corruption, given the ample presence of whistle-blowers in the media or the opposition. As a further illustration of our intuition at work, a recent article in The Economist observed that the Baltic countries had a better track record on corruption relative to other transition economies, suggesting that "because [their] governments are [relatively] weak and fast-changing, they are also limited in their ability to advance their financial backers' interests" (11 Dec 2004, p. 48). This is precisely the spirit behind the demand effect that we have outlined.

Importantly, we find strong support for our theory in the cross-country data: There is a robust quadratic U-shaped relationship between measures of corruption perception and measures of legislative stability. We document these findings at length in Section 3, where we show that the U-shape remains even when a battery of alternative determinants of corruption are included as control variables. In addition, we discuss some illustrative case studies for Brazil, Mexico and Kenya that suggest that the mechanisms underlying our theory, vis-a-vis the interplay between the demand and the horizon effects, can help us understand how corruption has ebbed and flowed in these countries as political stability has fluctuated. This suggests that our theory is also supported by within-country experiences. Last but not least, we also provide empirical evidence consistent with an additional implication of our model concerning the relationship between corruption and the size of government. We show in our model that the latter is positively related to stability, and hence also stands in a similar U-shaped pattern with corruption. Indeed, this prediction fares well when taken to the cross-country data.

Our paper falls within an extensive literature on the causes and consequences of corruption. ${ }^{6}$ A substantial amount of evidence has already been put forward concerning the latter,

\footnotetext{
${ }^{6}$ For an overview of issues, see Bardhan (1997) and Lambsdorff (1999).
} 
highlighting the deleterious effect that corruption has on growth and investment (Mauro 1995, and Knack and Keefer 1995). As for the former topic, a large volume of empirical work has identified various systematic determinants of corruption, including ethno-linguistic fractionalization (Mauro 1995), the presence of economic rents (Ades and Di Tella 1999), and low civil service pay (Van Rijckeghem and Weder 2001). This paper suggests that political stability also belongs on this list, as a key proximate variable driving the incentives for corruption. Our results also suggest a reason for the negative correlation between measures of democracy and corruption observed for example by Treisman (2000): In our schema, most competitive demographies are classified as having an intermediate level of stability, and hence experience lower levels of corruption than absolutist regimes or highly unstable polities. While political stability has previously been linked to outcomes such as aggregate growth (Alesina and Perotti 1996, and Alesina, Özler, Roubini and Swagel 1996), this is one of the first attempts to model formally a causal link to corruption. ${ }^{7}$

Several previous studies have alluded to a potential link between corruption and stability. Shleifer and Vishny's (1993) prediction that weak decentralized governments would have higher levels of corruption hints at a relationship with political instability, although their story works through a completely different mechanism - the lack of coordination among government agents. ${ }^{8}$ Elsewhere, Olson (1991, 2000) and DeLong and Shleifer (1992) discuss the importance of decision-making horizons on the behavior of incumbents, arguing that unstable rulers have greater incentives to appropriate or tax private wealth, of which corruption might be seen as a specific case. A form of this horizon effect is also captured to some extent in models of "electoral accountability", such as Barro (1973) and Ferejohn (1986). As for the demand effect, similar considerations are implicit in Rose-Ackerman's (1999) discussion of the importance of checks and balances on the government in curbing corruption.

The papers that are closest to ours are Fredriksson and Svensson (2002), and Le,

\footnotetext{
${ }^{7}$ Along these lines, there is also a well-developed literature on the links between corruption and politics. For example, Rose-Ackerman (1999) contains a comprehensive discussion of how the incentives for corruption vary under different political systems.

${ }^{8}$ Shleifer and Vishny (1993) arrive at this conclusion by assuming that private firms need to bribe different public officials to obtain licenses that are complementary to each other. Our model, by contrast, focuses on public officials who deal with corruption opportunities that are essentially unrelated.
} 
Mehlkop and Graeff (2004). The former paper analyzes how corruption and instability interact in influencing policy in a lobbying model. It contains ideas that resemble the horizon and demand effects, but does not deal with the impact of instability on corruption, taking instead the incumbent's propensity for corruption as an exogenous parameter. Separately, Le et al. (2004) find mixed empirical evidence on the interaction between corruption and instability, but their analysis adopts a much narrower measure of instability that focuses on the probability of regime change, and not the broader notion of policy instability that we advance.

The rest of this paper is organized as follows: Section 2 presents the basic model and an extension with endogenous stability, both of which generate a U-shaped relationship between corruption and political stability. Section 3 shows that this prediction of our theory is borne out by the cross-country evidence, as well as by some specific case studies. Section 4 concludes. Some details of the proofs and further extensions of the model are contained in the Appendix.

\section{A Model of How Instability Shapes the Incentives for Corruption}

\subsection{The Basic Model}

We assume that there is an incumbent who maximizes the ex ante expected sequence of incomes that he can obtain through two means, either: (i) Embezzlement, which entails direct appropriation of state resources; or (ii) Licensing, which involves granting private sector firms control over some of the resources, in exchange for an upfront payment. The probability that the incumbent and his policies survive from one period to the next is $\alpha$; there is no additional time discounting. In the event that the incumbent is ousted, we assume he receives zero payoff in all subsequent periods, and that the licenses he issued become void. The incumbent's problem is thus essentially an expected-income maximization problem - we implicitly assume that the incumbent can smooth his consumption over time, for example, by depositing the income in an offshore account. (We treat such funds as unrecoverable by the state even after the incumbent is ousted.) 
The initial pool of resources available in the economy is $K_{0}$. In each period $t$, the incumbent chooses an amount $E_{t}$ to embezzle and an amount $L_{t}$ to license. Let $\pi\left(L_{t}, \alpha\right)$ denote the ex ante expected value of profits reaped by the private firm from the license $L_{t}$. We assume that the incumbent has the ability to extract a fraction $\sigma$ of expected profits as upfront bribe payment for the license. We define corruption in each period, $\Gamma_{t}$, as the amount of illicit income that the incumbent receives, normalized by the resources available at the start of the period, namely:

$$
\Gamma_{t}=\frac{E_{t}+\sigma \pi\left(L_{t}, \alpha\right)}{K_{t}}
$$

The normalization is necessary in order to ensure that the measure of corruption is not subject to scale effects, so that larger countries are not deemed more corrupt simply because there are more resources that can potentially be appropriated by the incumbent.

In each period, the remaining untouched resources are transformed into the pool of resources available in the next period, subject to diminishing returns: $K_{t+1}=A\left(K_{t}-E_{t}-\right.$ $\left.L_{t}\right)^{\gamma}$. This has the interpretation of being a growth equation with technological parameter A. The sequence of events is summarized in Figure 1:

\section{[INSERT FIGURE 1]}

The sequence problem for the incumbent is thus:

$$
\max _{E_{t}, L_{t}} \sum_{t=0}^{\infty} \alpha^{t}\left[E_{t}+\sigma \pi\left(L_{t}, \alpha\right)\right] \quad \text { s.t. } \quad K_{t+1}=A\left(K_{t}-E_{t}-L_{t}\right)^{\gamma}
$$

We will focus on the case where the private sector's expected profit function is linear in $L_{t}$, namely: $\pi\left(L_{t}, \alpha\right)=\alpha A_{F} L_{t}$, where $A_{F}$ is the private sector technology parameter. This corresponds to a situation where the license is valid for one period only, period $t+1$, and production is undertaken with an $A K$ technology, subject to the possibility that the license is voided in the event of discontinuation of the incumbent's policies. ${ }^{9}$ The problem in $(2)$ can now be re-formulated as a Bellman equation with value-function $V(\cdot)$ :

$$
V\left(K_{0}\right)=\max _{E_{0}, L_{0}}\left\{E_{0}+\sigma \alpha A_{F} L_{0}+\alpha V\left(K_{1}\right)\right\} \quad \text { where } \quad K_{1}=A\left(K_{0}-E_{0}-L_{0}\right)^{\gamma}
$$

\footnotetext{
${ }^{9}$ The basic result concerning the U-shape obtains for a fairly general class of functional forms for $\pi\left(L_{t}, \alpha\right)$ with $\pi_{L}>0$ and $\pi_{\alpha}>0$. A particular case of interest is that of a concave production function, which we briefly present in the appendix.
} 
Solving this problem yields:

$$
\begin{aligned}
1 & =\alpha V^{\prime}\left(K_{1}\right) A \gamma\left(K_{0}-E_{0}-L_{0}\right)^{\gamma-1} \\
\sigma \alpha A_{F} & =\alpha V^{\prime}\left(K_{1}\right) A \gamma\left(K_{0}-E_{0}-L_{0}\right)^{\gamma-1} \\
V^{\prime}\left(K_{0}\right) & =\alpha V^{\prime}\left(K_{1}\right) A \gamma\left(K_{0}-E_{0}-L_{0}\right)^{\gamma-1}
\end{aligned}
$$

where (4) and (5) are the first-order conditions with respect to $E_{0}$ and $L_{0}$ respectively, while (6) comes from the Envelope Theorem. Clearly, (4) and (5) cannot both hold at the same time, except for a knife-edge scenario, which implies that one of the quantities $E_{0}$ or $L_{0}$ must be zero. (This is a consequence of the linear functional forms that we have used in this baseline model. In the Appendix, we establish our results in a specification that allows for both embezzlement and licensing to coexist in equilibrium.) In either case, substituting the right-hand-side of (6) into the relevant FOC that binds with equality, we arrive at the conclusion that $V^{\prime}\left(K_{t}\right)$ is a constant for all $t \geq 0$. Applying this fact to (6) yields:

$$
\begin{gathered}
K_{t}-E_{t}-L_{t}=(A \alpha \gamma)^{\frac{1}{1-\gamma}} \\
K_{t+1}=A\left(K_{t}-E_{t}-L_{t}\right)^{\gamma}=A^{\frac{1}{1-\gamma}}(\alpha \gamma)^{\frac{\gamma}{1-\gamma}}
\end{gathered}
$$

for all $t \geq 0$.

We therefore have two cases to consider:

Case 1: $\quad \sigma \alpha A_{F}>1$, ie $\alpha>\frac{1}{\sigma A_{F}}$

This is the case where the marginal gain from a small increment in $L_{0}$ exceeds that from a similar increment in $E_{0}$. Thus, the incumbent does not allocate any resources to embezzlement and corruption takes only the form of licensing revenues. Solving (5) leads to the following expressions for $L_{t}$ :

$$
\begin{aligned}
& L_{0}=K_{0}-(A \alpha \gamma)^{\frac{1}{1-\gamma}} \\
& L_{t}=K_{t}-(A \alpha \gamma)^{\frac{1}{1-\gamma}}=A^{\frac{1}{1-\gamma}}(\alpha \gamma)^{\frac{\gamma}{1-\gamma}}(1-\alpha \gamma), \quad \forall t \geq 1
\end{aligned}
$$

With $E_{t}=0$ for all periods $t$, the expressions for $L_{0}$ and $L_{t}$ from above are all that are 
needed to compute the expressions for corruption based on (1):

$$
\left.\begin{array}{l}
\Gamma_{0}=\sigma A_{F} \alpha\left[1-\frac{(A \alpha \gamma)^{\frac{1}{1-\gamma}}}{K_{0}}\right] \\
\Gamma_{t}=\sigma A_{F} \alpha(1-\alpha \gamma), \quad \forall t \geq 1
\end{array}\right\}
$$

Observe that corruption depends on the initial endowment of resources, $K_{0}$, only in the very first period $(t=0)$; from $t=1$ onwards, the model is in a "steady state" in which corruption remains constant, given the parameter values. In this basic framework, we have what we term a "cleaning-up" property, in which any amount of the period-0 endowment in excess of the steady state value of $K_{t}$ is consumed immediately and the economy reaches a steady state in one period. ${ }^{10}$ This model therefore delivers the stark prediction that any exogenous increase in the available endowment, such as through the injection of foreign aid, will be completely appropriated in the short run by the corrupt incumbent, while having no impact on the subsequent steady-state level of resources in the economy.

We consider two versions of the comparative statics for corruption with respect to $\alpha$ : (i) during the transition period (for $\Gamma_{0}$ ), and (ii) in steady state (for $\Gamma_{t}$ ). The difference between these two concepts has to do with whether the pool of resources at the start of the period is exogenous, or whether this is taken to be the steady state value of $K_{t}$. More precisely, a change in $\alpha$ will shift the economy towards a new steady state; $\Gamma_{0}$ thus captures the short-run behavior of corruption in transition, while $\Gamma_{t}(t \geq 1)$ describes the behavior of corruption in the new steady state. The respective comparative statics are as follows:

$$
\begin{aligned}
& \frac{d \Gamma_{0}}{d \alpha}=\sigma A_{F}\left[1-\frac{(A \alpha \gamma)^{\frac{1}{1-\gamma}}}{K_{0}}\left(1+\frac{1}{1-\gamma}\right)\right] \\
& \frac{d \Gamma_{t}}{d \alpha}=\sigma A_{F}(1-2 \alpha \gamma), \quad \forall t \geq 1
\end{aligned}
$$

Based on these expressions, we can see that corruption is increasing in $\alpha$, given some mild assumptions. Specifically, we require that $K_{0}$ be sufficiently large $\left(K_{0}>(A \gamma)^{\frac{1}{1-\gamma}}\left(1+\frac{1}{1-\gamma}\right)\right)$, so that $\frac{d \Gamma_{0}}{d \alpha}>0 .{ }^{11}$ As for all subsequent periods, a sufficient condition for corruption to

\footnotetext{
${ }^{10}$ The "cleaning-up" is a fairly general property, and holds whenever the incumbent's per-period utility is linear in $E_{t}$.

${ }^{11}$ To derive this condition, set $\alpha=1$ to get the smallest possible value of $\frac{d \Gamma_{0}}{d \alpha}$. It is easy to check that this condition on $K_{0}$ automatically ensures that $K_{0}$ exceeds the steady state value of $K_{t}$, so that we observe "cleaning up" of the excess resource endowment in the first period.
} 
be increasing in $\alpha$ is $\gamma<\frac{1}{2}$. Intuitively, we need that $\gamma$ be sufficiently small, so that diminishing returns set in fast enough in the accumulation equation for $K_{t}$, meaning that it does not become too attractive for the incumbent to set resources aside for the future. These comparative statics for the case where regimes are sufficiently stable $\left(\alpha>\frac{1}{\sigma A_{F}}\right)$ are driven precisely by the demand effect which operates through licensing: Firms are willing to pay higher bribes to more stable incumbents, and so corruption is increasing in stability.

Case 2: $\quad \sigma \alpha A_{F}<1$, ie $\alpha<\frac{1}{\sigma A_{F}}$

In this case, the marginal gain from licensing is smaller than that from embezzlement, and so $L_{t}=0$ for all $t \geq 0$. Using (4), one finds that:

$$
\begin{aligned}
& E_{0}=K_{0}-(A \alpha \gamma)^{\frac{1}{1-\gamma}} \\
& E_{t}=K_{t}-(A \alpha \gamma)^{\frac{1}{1-\gamma}}=A^{\frac{1}{1-\gamma}}(\alpha \gamma)^{\frac{\gamma}{1-\gamma}}(1-\alpha \gamma), \quad \forall t \geq 1
\end{aligned}
$$

From (1), corruption is then given by:

$$
\left.\begin{array}{l}
\Gamma_{0}=1-\frac{(A \alpha \gamma)^{\frac{1}{1-\gamma}}}{K_{0}} \\
\Gamma_{t}=1-\alpha \gamma, \quad \forall t \geq 1
\end{array}\right\}
$$

Both of these expressions are clearly decreasing in $\alpha$, hence corruption is decreasing in stability for $\alpha$ smaller than the cut-off value $\frac{1}{\sigma A_{F}}$. Here, the dominant force at play is the horizon effect, which operates through embezzlement: More unstable incumbents have a greater incentive to steal resources now instead of leaving them to future periods when they are unlikely to be around.

Bringing these two cases together, we find that our model generates $U$-shape of corruption with respect to stability, so long as $\frac{1}{\sigma A_{F}}<1$, so that the cut-off value of $\alpha$ lies in the interior of $[0,1]$. Note that the condition $\frac{1}{\sigma A_{F}}<1$ basically requires that the private sector be sufficiently productive or that the incumbent be able to extract a high enough share of profits, so as to make licensing worthwhile over some relevant range of stability. Moreover, a quick substitution of $\alpha=\frac{1}{\sigma A_{F}}$ into the above expressions for $\Gamma_{0}$ and $\Gamma_{t}$ from the two cases shows that corruption is indeed a continuous function of stability for all periods.

The logic that drives our U-shaped result is very intuitive. In the range of low stability, firms are unwilling to pay high bribes to unstable incumbents, so that embezzlement 
becomes the optimal option for self-enrichment. As a result, the horizon effect dominates: Corruption falls as the incumbent's stability improves and the incentive to embezzle decreases. Beyond a certain level of stability, however, licensing becomes the more profitable option, as sufficiently stable incumbents are able to extract larger bribes from firms. Therefore, the demand effect prevails in the range of high stability: Corruption increases as stability improves, since firms are willing to offer ever larger amounts of bribes.

We can now state our central proposition on how stability stability affects corruption:

Proposition 1 [U-Shape] Suppose that $K_{0}$ is sufficiently large, $\gamma<\frac{1}{2}$, and $\sigma A_{F}>1$, so that $\alpha^{*}=\frac{1}{\sigma A_{F}} \in[0,1]$. Then per-period corruption is (strictly) decreasing in stability $\alpha$ for $\alpha<\alpha^{*}$, and (strictly) increasing in $\alpha$ for $\alpha>\alpha^{*}$. This holds both in steady state $(t \geq 1)$ and in the transition to the steady state $(t=0)$.

This U-shaped pattern is the key testable prediction of our model. We illustrate it graphically in Figure 2, for some reasonable choices of parameter values.

\section{[INSERT FIGURE 2]}

Beyond the U-shaped relationship, the model also yields a couple of interesting predictions relating to the effects of parameter shifts:

Proposition 2 [Comparative Statics] Based on the expressions for corruption in (7) and (8), it follows that:

(i) Corruption is weakly increasing in the government's bargaining power vis-a-vis the private sector, $\sigma$, and the productivity of the private sector technology, $A_{F}$.

(ii) In response to a given rise in $\sigma$ or $A_{F}$, the increase in corruption is larger when the incumbent is more stable (ie $\alpha$ is higher).

Proof. By inspection of (7) and (8), it is clear that $\sigma$ and $A_{F}$ increase corruption from licensing while not affecting corruption from embezzlement. This establishes part (i) of the proposition. For part (ii), it is easy to check from (7) that the cross-derivative between $\sigma A_{F}$ and $\alpha$ is positive, so long as $\Gamma_{0}$ and $\Gamma_{t}$ are increasing in $\alpha$. 
This proposition lends itself to a natural interpretation. Part (i) follows from the fact that corruption revenues from the private sector rise when either the bargaining position of the government is strengthened or when the private sector's technology improves. As for part (ii), notice that $\sigma$ and $A_{F}$ affect the corruption revenues from licensing, but not from embezzlement. As a result, these parameters gain salience in the range of $\alpha$ where licensing dominates, resulting in a larger increase in corruption when the incumbent is more stable. ${ }^{12}$

Later in Section 3, we present some empirical evidence to test various predictions of our model. However, we turn first to an extension.

\subsection{An Extension: Endogenous Stability}

Up until now, we have made the simplifying assumption that stability $\alpha$ is an exogenous parameter. Naturally, however, one would expect that the stability of the government should depend on its level of public support, which in turn would be affected by the resource allocation decisions it makes. In this subsection, we develop a simple, tractable extension in which stability is endogenously determined by the amount of public goods that the incumbent chooses to provide. We do not take a stand on what these public goods are - they could include education, health, infrastructure - or how they are produced. The provision of these goods will be assumed to boost the incumbent's stability, for example, because the public (as distinct from the private sector) derives benefits from consuming them. However, this reduced-form formulation does not preclude an interpretation in which this expenditure to increase stability may involve some form of repression, such as military or police spending, instead of more benign forms of public goods. Likewise, one could think of this spending as patronage strategically dispensed by the incumbent to cultivate political support from key voters or political players. The important thing for the model is that from the point of view of the incumbent, this expenditure diverts resources away from his pocket. In what follows, we show that this extension does not alter the main properties of the basic model, and indeed provides some additional testable predictions.

\footnotetext{
${ }^{12}$ It could be the case that $\sigma$ increases with $\alpha$, since one might expect more stable incumbents to command more bargaining power over the private sector. This is a simple extension that would only reinforce the upward-sloping relationship between corruption and stability for high levels of $\alpha$.
} 
The game structure is the same as before, except that the government now has to decide in each period how much of $K$ to set aside for the provision of public goods. We model stability as depending on: (i) the intrinsic stability of the polity, denoted by $\zeta$, and (ii) a function of the government's choice of public good provision, denoted by $g(P)$, where we assume $g(\cdot)$ to be increasing and concave, with $g(0)=0$. We interpret $\zeta$ as an exogenous, "systemic" level of stability determined by deep-seated features of the polity that are largely beyond the incumbent's control, such as the ethnic composition of the population or cultural norms. These deep-seated features can in turn be mapped into a desired level of public goods provision, $P_{\zeta}$, where $g\left(P_{\zeta}\right)=\zeta$. For instance, following Alesina, Baqir and Easterly (1999), a more fractionalized polity would in equilibrium have a lower desired level of public goods provision, since each individual would attach a lower value to public goods consumption by other individuals who do not belong to the same ethnic group. We thus think of $P_{\zeta}$ as establishing a "ceiling" on stability, whereby any shortfall of public goods provision with respect to this reference level will weaken the incumbent's position. We thus model stability, $\alpha$, as follows:

$$
\alpha=\min (\zeta, g(P))
$$

with $\zeta \in[0,1]$. Note that this formulation boils down to an assumption that public goods provision and intrinsic stability are (perfect) complements from the standpoint of how they contribute to $\alpha$. In other words, polities that are intrinsically more stable allow an incumbent to better translate spending on public goods into enhanced stability. ${ }^{13}$

The incumbent's problem from our baseline case, (3), can now be adapted as follows:

$$
\begin{aligned}
V\left(K_{0}\right) & =\max _{E_{0}, L_{0}}\left\{E_{0}+\sigma \min \left(\zeta, g\left(P_{0}\right)\right) A_{F} L_{t}+\min \left(\zeta, g\left(P_{0}\right)\right) V\left(K_{1}\right)\right\} \\
\text { where } K_{1} & =A\left(K_{0}-E_{0}-L_{0}-P_{0}\right)^{\gamma}
\end{aligned}
$$

By solving this problem, we can derive the following:

\footnotetext{
${ }^{13}$ It can be shown that our results still hold when there is sufficient complementarity between the exogenous and the endogenous components of stability, namely between $\zeta$ and $g(P)$. Intuitively, when public goods provision complements intrinsic stability, both $\zeta$ and $g(P)$ co-vary together, rendering the model similar to our basic set-up without the endogenous component.
} 
Proposition 3 [Generalized U-Shape] Suppose that $g(P)$ belongs to the class of increasing concave functions $g(P)=(c P)^{\rho}$, and moreover that $\gamma<\frac{1}{2}$ and $A$ and $K_{0}$ are sufficiently large. Then in steady state, there exists an $\alpha^{* *} \in[0,1]$ such that per-period corruption is (strictly) decreasing in stability $\alpha$ for $\alpha<\alpha^{* *}$, and (strictly) increasing in $\alpha$ for $\alpha>\alpha^{* *}$.

Proof. While the details of the proof are left to the Appendix, we sketch here the basic intuition. Consider first the solution of the "unconstrained" problem, namely when $g(P)$ exceeds $\zeta$ :

$$
\begin{aligned}
V\left(K_{0}\right) & =\max \left\{E_{0}+\sigma A_{F} g\left(P_{0}\right) L_{0}+g\left(P_{0}\right) V\left(K_{1}\right)\right\} \\
K_{1} & =A\left(K_{0}-E_{0}-L_{0}-P_{0}\right)^{\gamma} .
\end{aligned}
$$

Let the level of public goods provision obtained from solving this problem be $\bar{P}$, and the corresponding level of intrinsic stability be $\bar{\zeta}=g(\bar{P})$. Then $\bar{P}$ will be the amount of public goods provision whenever $\zeta \geq \bar{\zeta}$. Stability $\alpha=g(\bar{P})$ will be a constant, and hence corruption will also be constant over this high enough range of $\zeta$. For $\zeta<\bar{\zeta}$, the incumbent will choose $P=P_{\zeta}$, so that $\alpha=\zeta$, and the problem becomes essentially identical to the model with exogenous stability. Consequently, under some mild conditions on $\gamma, A$ and $K_{0}$, the Proposition holds for the class of functions $g(P)=(c P)^{\rho}$, in which there are diminishing returns in the extent to which public goods can contribute to improving stability. We thus have a "generalized" U-shape, or a "root" shape $(\sqrt{ })$, of corruption with respect to systemic stability $\zeta$. This translates into a U-shape between corruption and stability $\alpha$, just as in Proposition 1, since $\alpha$ is constant for over the horizontal end of the "root" shape.

It is straightforward to see that the comparative statics results from Proposition 2 continue to hold in this extension. Of particular note, we are also in a position to derive some new testable implications concerning how corruption and stability co-vary with the level of public goods provision. In our model, we interpret public goods provision as equivalent to the size of government, given that $P$ is the only form of government expenditure. We state our result as follows: 
Proposition 4 [Size of Government] Given the same parameter conditions as in Proposition 3, corruption is U-shaped with respect to the size of government.

Proof. Public goods provision is weakly increasing in the level of intrinsic stability, given the complementarity between these two $\zeta$ and $P$. The U-shape between corruption and the size of government then follows from the fact that corruption and (intrinsic) stability stand in this by-now familiar U-shaped relationship.

In words, governments which are either very small or very large are associated with more corruption, but those of an intermediate size witness lower levels of corruption. In our model, the reason behind this pattern is that governments are very small or very large because they are (respectively) intrinsically highly unstable or highly stable, and both of these extremes are associated with high levels of corruption.

\section{Empirical Tests of the Model}

In the previous section, we developed a model that generates a stylized U-shaped relationship between corruption and stability, based on the interplay between the horizon effect and the demand effect. We turn now to some evidence in support of our model. We start by showing that there is a systematic and robust U-shaped pattern linking corruption and stability at the cross-country level (Section 3.1 ). We then turn to some country case studies which serve to illustrate how corruption takes the form of both licensing and embezzlement in practice, as well as how their interaction conforms with the story that underlies our theory (Section 3.2). Finally, we offer an additional test related to the existence of a U-shaped relationship between corruption and the size of government, which confirms a key corollary of our model (Section 3.3).

\subsection{A Stylized Fact on Corruption and Stability}

Following much of the empirical literature on corruption, we focus on indices of corruption perception based on institutional assessments or surveys, in light of the difficulty of obtaining more precise measures on the magnitude of such secretive transactions. While 
several recent studies, such as Svensson (2003) on Uganda and Olken (2004) on Indonesia, have made significant advances in gathering more direct objective measures of corruption, it remains a major challenge to obtain data of this nature on a comparable basis for a large sample of countries.

Our main measure of corruption is from the KKM governance indicators data set, one of the most comprehensive attempts to pool together indices of corruption perception from disparate sources. In all, 25 indices gathered by up to 18 organizations are aggregated using an unobserved components methodology, which helps to reduce the effects of subjective biases that might be inherent in any single data source. We use the negative of KKM's "Control of Corruption" index, scaled between -2.5 and 2.5, so that higher values indicate more corruption. ${ }^{14}$

To capture political stability, we use two different variables from the Database of Political Institutions (DPI) by Beck et al (2001). The first is the share of seats in the legislature occupied by the governing party or coalition, termed "Majority" for short. We view this as a measure of the strength of the incumbent's position, since a higher government share would reduce the likelihood that the opposition can impede policy decisions or oust the incumbent. The DPI also provides a second alternative measure in the form of an opposition Herfindahl index, which is the sum of squared seat shares of the opposition parties. We subtract this Herfindahl index from one to obtain a fractionalization index ("FracOpp"), so higher values indicate a less united opposition and hence greater stability for the incumbent. Our preferred measure of stability is "Majority", given that "FracOpp" captures first and foremost the weakness of the opposition, and is thus a more indirect measure of

\footnotetext{
${ }^{14}$ There are several reasons why we have used the KKM index instead of another well-publicized source, the Transparency International (TI) index. Although the TI index is also an aggregate of scores from different agencies, it is based on fewer sources (10) than KKM, and covers fewer countries (only 91 states in the 2000 edition, compared to 185 in KKM). Moreover, KKM (2004) show quite convincingly that the aggregation methodology used by TI generates estimates that are less precise than theirs. In particular, TI takes a simple average of scores, as opposed to a precision-weighted average in KKM. Also, the more recent years of the TI index use a bootstrap procedure to generate estimates of standard errors, but KKM argue that these errors are downward-biased when the number of component indices for the aggregate is small. (For more details on the TI methodology, see Lambsdorff (2002).) For completeness, we present in Appendix Table 1 some results using the TI index.
} 
incumbent stability. ${ }^{15} \quad 16$

Table 1 presents our results on the relationship between corruption and "Majority". All of the regressions are run with year fixed effects, as the normalization that KKM adopt has the property that the numerical values of the corruption index cannot be compared cardinally across years. We use one-year lagged values for all the explanatory variables such as our proxies for stability, in order to reduce the possibility of reverse causality. As the DPI sample stops in 2000, this means that we are only able to use the KKM data from 1996, 1998 and 2000. Given the small number of observations per country (at most three), we focus on the cross-country variation and thus do not include country dummies. Nevertheless, we allow for within-country correlation in the error terms by computing robust standard errors clustered by country. ${ }^{17}$ To balance the panel, we include in each regression only those countries for which all three years of data were available for all the variables.

The main result centers on the U-shaped relationship between corruption and our measures of stability. Throughout Columns (1)-(8), we find significant coefficients on "Majority" and its square, along with an implied turning point that is remarkably stable, around $0.6-0.7$, thus well within the relevant range of data. Corruption is thus decreasing in stability for low ranges of "Majority", while increasing in stability at high ranges. Using the estimated bivariate normal distribution of the coefficients of "Majority" and its square, we computed a Monte Carlo probability (based on 100,000 independent draws) that the turning point lies within $[0,1]$. The results of this exercise show a high level of confidence (with probability greater than 0.95 across all specifications) that the turning point of the U-shape is indeed interior. ${ }^{18}$

\footnotetext{
${ }^{15}$ For example, in the extreme case where the opposition occupies only one seat in the legislature, "FracOpp" would be equal to 0, which vastly understates how secure the incumbent really is.

${ }^{16}$ Although measures of observed incumbent turnover are often used to gauge instability, these are not well-suited for our present application. First, such measures are ex post outcome measures when what we want to look at are ex ante probabilities of instability. Second, these measures do not capture fully the concept of policy instability, vis-a-vis the obstruction of the incumbent's decisions, that we have laid out in the Introduction.

${ }^{17}$ Note that each data point on corruption comes with an associated standard error from the KKM aggregation procedure. Since this variable is being used on the left-hand-side of our regressions, it is important to allow for heteroskedasticity by computing Huber-White robust standard errors.

${ }^{18}$ We choose to report this statistic instead of a more conventional $95 \%$ confidence interval, since the distribution of the point estimate for the turning point displays a lot of right skew. This is because the expression for the turning point involves the quotient of the two coefficients; when the draws for the
} 
The above results hold even when controlling for a measure of log real GDP per capita (in 1995 US dollars) taken from the World Development Indicators (WDI) (Column (2)). The inclusion of this income variable helps to control for the possibility that errors in the measurement of the corruption index might be systematically correlated with a country's overall economic performance. Not surprisingly, the income coefficient comes out negative and highly significant, so richer countries are generally perceived as less corrupt. More importantly, its presence does not weaken the U-shaped relationship, confirming that the stability variable is indeed picking up some systematic correlate of corruption and not merely proxying for output per capita. These results are further robust to controlling for a full set of region dummies in Column (3).

The rest of Table 1 confirms the robustness of the U-shape to the inclusion of other potential determinants of corruption proposed in the literature. We include in Column (4) a measure of ethnolinguistic fractionalization (ELF) (from Alesina et. al. (2003)) and a dummy for British legal origin: Consistent with Mauro (1995), we find that ELF increases corruption, and as found in Treisman (2000), British legal origin is associated with less corruption. In Column (5), we add an oil exporter dummy to capture the availability of expropriable rents, and the import share of GDP (from the WDI) to get at the degree of competition in the domestic economy, in line with the hypothesis in Ades and DiTella (1999) that the former should increase corruption while the later should reduce graft. Throughout these exercises, the inclusion of these alternative explanations for corruption never detracts from the statistical significance of the U-shape with respect to "Majority". Column (6) shows that this result persists even when we control for the two-year lagged value of corruption. ${ }^{19}$ The results so far are graphically illustrated by Figure 3, which plots the corruption residuals (controlling for all Column (4) covariates except "Majority" and its square) against "Majority" itself.

At this point, one might expect "Majority" to be a better proxy for stability in sufficiently vibrant democracies where the legislature is an effective platform for checking the policies of the incumbent. To investigate this, we restrict the regression in Column (7) to denominator value are small, this is magnified into large estimates for the turning point.

${ }^{19}$ The results in Table 1 are very similar if we also control for the square of log real GDP per capita. 
countries with a minimum Polity IV democracy (DEM) score of at least 5 (on a scale of 0 to 10) over the three years in our dataset. ${ }^{20}$ Reassuringly, the significance of the U-shape with respect to "Majority" is preserved in this sub-sample. Column (8) presents an alternative way of parsing the data using the Legislative Index of Electoral Competitiveness (LIEC) from the DPI. This index takes integer values from 1 (states with no legislature) to 7 (states where the largest party occupies less than $75 \%$ of legislative seats). We restrict the sample to countries with a LIEC score of at least 5, which leaves the set of all countries where multiple parties are legal; once again, this does not reduce the significance of the U-shape. ${ }^{21}$ Moreover, our results continue to hold even if the democracy or LIEC variable are included directly in the regression as covariates. ${ }^{22}$

Table 2 repeats this exercise using the alternative measure of stability, "FracOpp". The qualitative results and in particular the U-shape between corruption and stability are successfully replicated for the main sample in Columns (1)-(5), although the coefficients lose their significance when lagged corruption is included or when the sample is restricted to sufficiently democratic or competitive polities in Columns (7)-(8). Nevertheless, the probability that the turning point lies in the interior of $[0,1]$ remains high as before, being larger than 0.85 . Note that as a measure of how disunited the opposition is, "FracOpp" would arguably be a better proxy for the incumbent's stability if we were to first take into account the strength of the government's position in the legislature. We thus also experimented with alternative indices of stability that are a composite of both "Majority" and "FracOpp", such as their interaction or their mean. While we do not report these regressions, the significance of the U-shape in these specifications was very similar if not stronger than the results in Table $2 .^{23}$

\footnotetext{
${ }^{20}$ The results are largely unchanged if a cut-off of 4 or 6 is used instead.

${ }^{21}$ These two alternative ways of restricting the sample are not equivalent. In particular, the condition that the minimum DEM score be at least 5 is a slightly more stringent criterion, as there are 40 countries for which minimum LIEC $\geq 5$, but minimum DEM is less than 5 . Conversely, there are only 4 countries which have minimum DEM $\geq 5$, but minimum LIEC $<5$.

${ }^{22}$ When the democracy variable is included on the right-hand-side, it has a negative a significant coefficient, consistent with Treisman (2000) who found that democracies are less corrupt.

${ }^{23}$ Given the disadvantages of the TI index highlighted in footnote 14 above, namely the smaller sample size and the lower precision of its estimates, it is not surprising that we obtain larger standard errors and lower significance levels in Appendix Table 1 where we replicate the regressions using the TI measure. Nevertheless, the point estimates continue to imply a U-shape with respect to stability.
} 


\subsection{Some "Real World" Illustrations}

We supplement the cross-country evidence above by providing some illustrative case studies of how stability has affected corruption in practice. In particular, these examples highlight the relevance of the distinction we draw between corruption as licensing and corruption as embezzlement, and show how their interaction with the incumbent's stability accords in practice with the mechanisms that drive our theory.

\subsubsection{Brazil}

Brazil in the 1990s is a very clear example of a country that started with very low levels of stability and high levels of corruption, but which later transitioned into a less corrupt regime as stability improved. Its experience is entirely consistent with the "decreasing arm" of the U-shape between corruption and stability.

In the 1980s, Brazil underwent a transition from military rule to democracy. The first civilian government in two decades took office in 1985, and the first presidential election in 29 years was held in 1989. That election was won by Fernando Collor de Mello, who a year before was the little-known governor of one of Brazil's poorest states, and who had come to prominence with the proclaimed goal of fighting corruption. However, in 1992, he became the first Brazilian president to be impeached, as evidence of widespread and rampant corruption mounted against him and his closest associates. In the words of Geddes and Ribeiro Netto (1999, p. 22), it is apparent that "corruption did increase in Brazil during the 1980s and early 1990s... The amounts of money described and numbers of people implicated in corruption schemes investigated... are substantially greater than those described in earlier inquiries." Skidmore $(1999$, p. 8) goes on to describe the levels of corruption during the Collor administration as "unprecedented".

One feature consistently stressed by many scholars that have studied this period is the high levels of what we call "policy instability". ${ }^{24}$ The electoral rules created during the democratic transition, largely as a response to the period of authoritarian rule, led to the proliferation of a large number of political parties, of which no less than 17 were

\footnotetext{
${ }^{24}$ What follows draws mostly upon Skidmore (1999), Geddes and Ribeiro Neto (1999) and Souza (1999).
} 
represented in Congress by 1990. In fact, the three largest delegations did not add up to a simple majority. This made it extremely hard for the executive to build a stable coalition. In this scenario, Collor emerged as the presidential candidate of a small party that he had himself just founded, the National Reconstruction Party (PRN). Despite winning the presidential election, the PRN had only $6.3 \%$ of the seats as the new administration took office. ${ }^{25}$ Unable to muster consistent support in parliament, Collor resorted to the so-called medidas provisórias to try to push through his desired policies: These were "provisional measures" which had the force of law for up to 30 days, during which time Congress could either reject them or pass them. However, during 1990, both Congress and the Supreme Court showed increasing resistance to Collor's use of this policy tool, culminating in February 1991 when "a Congressional revolt forced Collor virtually to give up his use of the instrument" (Skidmore, 1999, p. 5). It is thus clear that the president's ability to push through his policies was severely limited, and Geddes and Ribeiro Neto (1999) argue explicitly that this institutional setup was central in explaining the increase in corruption.

This situation was compounded by the fact that public officials had short time horizons for their duration in office. Noting that corruption was not limited to the president and his closest associates, Geddes and Ribeiro Neto (1999) stress that, in light of their unimpressive professional status, "many of the appointed members of Collor's original team could expect only a short term in office... [and] the temptation to 'take the money and run' increased" (p. 42). In short, there is clear evidence of a link between an environment of high policy instability and high levels of corruption, with a strong embezzlement component. ${ }^{26}$

Nevertheless, the corruption situation appears to have improved in Brazil as stability increased over time, as is consistent with our theory, to the extent that this did not push the country all the way to the other end of the stability spectrum. After Collor's impeachment,

\footnotetext{
${ }^{25}$ The party's lack of substance is illustrated by the fact that it had ceased to exist by the mid-1990s, after its founder's demise.

${ }^{26}$ This is not to say that corruption took place exclusively in the form of embezzlement. During the Collor administration, it is clear that bribe-taking and licensing were also rampant. As Geddes and Ribeiro Neto (1999) point out, the Collor administration implemented a freeze in bank accounts which created "a near monopoly [by the government] on liquid assets in the country" (p. 43). This can be interpreted as a large increase in $\sigma$ in our model, with a predicted increase in corruption and in the attractiveness of licensing. In their words, "commissions, kickbacks, and the emergence of collusion between businesspeople and officials were the natural consequences of dependence and monopoly" (p. 43).
} 
both the Itamar Franco (1992-1994) and the Fernando Henrique Cardoso administrations (1995-2002) are widely seen to have been considerably less corrupt than Collor. Geddes and Ribeiro Neto (1999) argue that the "take the money and run" temptation "has lessened in post-Collor administrations. Franco's appointees... had every reason to expect their careers in public life to continue afterward [and] Cardoso's appointments to high-ranking positions include many of the best economists in the country, as well as able professionals in other fields... [S] uch appointees have a longer time horizon" (p. 42). Moreover, the coalition that elected Cardoso held nearly one-half of all congressional seats, and was reputed to be "fairly stable", while Cardoso himself "comes from a party of respectable size and reasonable coherence" (p. 45). Add to this scenario the approval of a constitutional amendment allowing for reelection to executive offices, and what emerges is a context of significantly improved policy stability. ${ }^{27}$

We conclude that the case of Brazil in the 1990s provides supportive evidence of the mechanisms behind the "decreasing arm" of the U-shape in our theory. Some evidence pertaining to the "increasing arm" can be gleaned from the next country example.

\subsubsection{Mexico}

Mexico illustrates the converse phenomenon: A country that started with very high levels of stability and corruption, which later became less corrupt as the absolute stability of the regime decreased.

Starting in 1929, the Institutional Revolutionary Party (PRI) was in power in Mexico for more than seven decades without interruption. This was undoubtedly a remarkably stable regime, which Preston and Dillon (2004) describe as a "quasi-single-party system". It featured a strong degree of centralization of power in the hands of the president, who controlled the party and all state governors - in short, his powers were "almost those of a monarch" (p. 52). The legislature, heavily dominated by the PRI, basically rubberstamped the president's decisions, since the president himself selected the party's candidates for congressional posts. Similarly, the judiciary was for the most part toothless in the

\footnotetext{
${ }^{27}$ Incidentally, the approval of the reelection amendment can be nicely interpreted within the context of our model with endogenous stability, as public spending was devoted to increase actual stability in a setup where "intrinsic" stability was also improving.
} 
executive's will in check. Although reelection was prohibited, the fact that the president got to pick the party's candidate for his succession - which amounted to anointing his successor, in a process nicknamed dedazo ("finger tap") - and the "unwritten rule that former presidents and their families would not be criticized, let alone prosecuted" (p. 57) both guaranteed that the system would embed very long political horizons. In sum, policy stability was very high.

Our theory would therefore predict that high levels of corruption would result, as is indeed the conclusion of just about every observer. According to Preston and Dillon (2004), "among the system's basic codes of conduct, corruption seemed to be one of the most fundamental" (p. 57). In such an environment, our theory would predict that licensing should be an important part of the way corruption manifested itself. This is clearly confirmed by existing accounts: "With business heavily dependent on government contracts, the lines between the public and private sectors were often blurred. An executive receiving a substantial government contract would include in his cost calculations, as a matter of course, a commission for the official who approved the deal... [G] overnment officials often became silent partners in the deals they authorized" (p. 184). ${ }^{28}$ Indeed, the link between stability and corruption in the PRI regime has not gone unnoticed: "Authoritarian rule tended to breed corruption. Because PRI officials were finally accountable to no one but the President, it behooved special interests to ply them with bribes, and with the President drawn from the same party over the decades, incoming administrations had little incentive to clean house or punish abuses by their predecessors" (p. 326).

Starting in the 1990s, however, stability started to decrease towards a more moderate level consistent with a better-functioning democracy, and this transition appears to have been accompanied by some reduction in the prevalence of corruption, consistent with our model. Ernesto Zedillo became president in 1994 after the dedazo system was disrupted by the assassination of President Salinas's anointed successor. Zedillo implemented reforms in the electoral process that reduced the party's control over election results, and in 1997,

\footnotetext{
${ }^{28}$ The involvement of high levels of the administration in corruption as licensing is illustrated by the well-documented misdeeds of Raúl Salinas during his brother Carlos Salinas's tenure as president (19881994).
} 
for the first time in modern Mexican history, the PRI was left with less than $50 \%$ of the seats in the lower house of the Congress. As a culmination of this process, the opposition won the 2000 presidential elections with Vicente Fox. Fox's party, however, controlled less than $40 \%$ of the seats in both houses. Under these circumstances, "democratic checks were restricting his powers to a degree faced by no previous Mexican president... [T]he Congress had become far more assertive, defeating a considerable percentage of the bills he proposed and rewriting everything" (p. 514).

With regard to the effects of this decreased stability on corruption, although there is widespread disappointment in that Fox did not live up fully to high public expectations, it has nevertheless been argued that the administration "has actually made important investments in the future of clean government ... bringing the anticorruption agency up to global standards" (Rosenberg 2003). An acclaimed "freedom of information act" was also implemented. This suggests that corruption has decreased some: Indeed, on the KKM measure of corruption, Mexico went from a rank of 91 out of 151 countries in 1996 to a rank of 71 out of the same set of countries in 2002. In short, the Mexican experience of falling corruption as stability improved is consistent with the "increasing arm" of our U-shape.

\subsubsection{Kenya}

The Kenyan experience provides an African example of how the nature of corruption has evolved as the stability of a longtime incumbent declined over time. In particular, there is some anecdotal evidence that corrupt deals and kickbacks between the private sector and public officials declined after Mwai Kibaki ended Daniel Arap Moi's 24-year tenure as Kenya's president, while the stealing of state resources persisted and perhaps even worsened in the early tentative years of Kibaki's presidency. This provides support for a key prediction of our model, namely that bribes for long-term licenses will decline as the political stability of the incumbent becomes more uncertain, while being replaced by more short-term stealing and embezzlement. ${ }^{29}$

Daniel Arap Moi ruled Kenya as president from 1978-2002. Prior to 1991, his position

\footnotetext{
${ }^{29}$ Note that this is not to suggest that there was no direct stealing under Moi's rule, only that illicit agreements and contracts with the private sector were more prevalent.
} 
was virtually unchecked as his Kenya African National Union (KANU) party held full control of the legislature (a "Majority" of 1). Formal opposition parties were even banned by the constitution in 1982. In this environment of very high incumbent stability, Moi's rule was marked by the existence of strong ties between the political establishment and the private sector. A report in The Economist in 1991 described the economy as one where "[p]oliticians and senior civil servants own private firms, whose prosperity depends upon the support of politicians and senior civil servants". Moreover, "investment - especially in dams, roads and big projects financed by foreign aid - has been seriously distorted by pressure for 'commissions'. Powerful figures have enforced personal monopolies" (30 Nov 1991, p. 42). In short, the economic system under Moi's absolute rule was one where private businesses had to establish political connections and bribe government officials in order to obtain the necessary permits and licenses to operate.

Even though Moi relented to foreign pressure for political reform in 1991 and opened the country to multi-party elections the subsequent year, he nevertheless manipulated Kenya's tribal politics to stay in power. Although his KANU party only managed to hold a parliamentary majority of just over $50 \%$ of the legislative seats between 1992 and 2002, the opposition against him was very fractionalized, with the concentration (Herfindahl index) of opposition seats being a meagre 0.22 in 2000. During this time, businessmen with close connections to Moi were still able to establish "vast empires in real estate, tourism and agriculture" (Wrong 2002). In fact, Kenya ranked as one of the most corrupt countries in the world, ranked 138 out of 151 in 1996 on the KKM measure.

The December 2002 elections marked a major milestone in Kenya's political history, as Moi's KANU party was voted out on a wave of public frustration against the economic deterioration and corruption during his rule. One can argue that this ushered in a period of increased policy instability for the country. Although the new president Mwai Kibaki and his National Rainbow Coalition (NARC) secured $60 \%$ of the legislative seats, the opposition remained fairly strong, with KANU securing 64 out of 85 opposition seats (a Herfindahl of 0.60). Moreover, the uncertainty has been compounded by reports of Kibaki's ill health (The Economist Global Agenda 2004). 
During this period of increased instability, a $B B C$ News article observed that "the nature, if not the fact, of corruption is changing" The owner of a local engineering company was quoted saying that "previously it was difficult to get government contracts unless you had political connections. The new government's initiative on corruption has made many businesses nervous ... as they now face real competition" (BBC News 2004). This is exactly what our model would predict: Corruption in the form of licensing should decrease amid a climate of increased instability. Moreover, the anecdotal evidence indicates that corruption in the form of pure stealing or embezzlement has continued, if not worsened, despite the Kibaki government's attempts to reel it in. In July 2004, the British high commissioner to Kenya, Edward Clay, publicly noted that Kenya's old official corruption appeared to have been replaced by a "new corruption". Clay voiced concerns that as much as $\$ 188$ million had been siphoned away by dishonest officials in the first 19 months of Kibaki's presidency (The Economist Global Agenda 2004). During this time, top members of the presidents' office were also accused of pocketing up to $\$ 34$ million that was set aside to improve Kenya's passport and visa system. Separately, international donors have estimated that as of early 2005, \$1 billion of foreign aid had disappeared since 2002, nearly a fifth of the nation's budget for 2004 (Wax 2005).

In short, Kenya appears to have moved from one end of our U-shaped spectrum to the other, as corruption as licensing has decreased while embezzlement continues to be rampant.

\subsection{Corruption, Public Goods and the Size of Government}

In this final section, we present evidence supporting our model's prediction of a U-shaped pattern between corruption and the size of government, as established in Proposition 4. This topic has drawn some recent attention in the literature. Alesina and Angeletos (2004) present a model in which a positive relation between corruption and size of government is taken as a premise, whereby a larger government implies a larger scope for rent-seeking activities. However, this relationship has not been easy to verify: Glaeser and Saks (2004), for example, find no significant correlation between corruption convictions and the size of government at the state level in the United States. Understanding the nature of the 
relationship between these variables is clearly an important topic in its own right, given the policy implications that it bears on what an appropriate size of government might be in order to minimize the incentives for public officials to engage in corrupt activities.

We proceed in Table 3 to test Proposition 4. We use total government expenditures as a share of GDP to proxy for the size of government, where this data was taken from the World Bank's Global Development Network Growth Database (GDNGD). Conceptually, we see public spending by the incumbent as a means of bolstering his own stability, either through the provision of public goods to generate widespread support, by channelling resources to domestic law enforcement agencies to strengthen the instruments of coercion, or by disbursing patronage to key constituencies. Columns (1)-(4) present the relationship between the KKM corruption index and this size of government measure, for the sample of countries that provided the relevant government data for both 1996 and 1998. (All regressions are run with year fixed effects and standard errors are clustered by country.) At first glance in Column (1), there appears to be a significant negative correlation between corruption and government size across countries. But this turns out to be misleading, as the inclusion of a square term in Column (2) reveals a significant U-shape. Column (3) includes the one-year lagged WDI measure of real GDP per capita to control for components of the corruption index that might be driven by income levels. This weakens the significance level of the U-shape, but does not change the signs of the relevant coefficients.

The inclusion of region dummies in Column (4) restores the significance of the Ushape between corruption and the size of government. The partial scatterplot in Figure 4 clearly illustrates this relationship, where the vertical axis plots the residuals obtained from regressing the KKM index against log real GDP per capita and year fixed effects. Importantly, the minimum point of the U-shape is at a level of total expenditures equal to about $36 \%$ of GDP, a figure that sits within the interior of the range of government sizes observed in the sample (from 8\%-48\%). Note that the significance of our results is not weakened by the removal of the one potential outlier (from Italy) in the Northeast corner of the graph (regression not shown). A Monte Carlo simulation along the lines of those performed in previous sections shows a high probability of the turning point being in the 
relevant range, further confirming the existence of the U-shape.

In sum, we find empirical validation for this corollary of our model: There is indeed good evidence of a U-shaped pattern relating corruption to the size of government.

\section{Concluding Remarks}

This paper has prsented a theoretical model linking the level of corruption to the degree of instability that political incumbents are exposed to. Our explanation starts from the recognition that corruption can assume two forms, namely embezzlement and licensing/bribery. It then builds on the interaction between two effects: The horizon effect, by which a less stable incumbent is more willing to steal, and the demand effect, according to which higher bribes will be offered to a more stable incumbent. Since firms are unwilling to offer substantial bribes to highly unstable incumbents, embezzlement is the prevailing form of corruption at low levels of stability and hence the horizon effect dominates. Conversely, the demand effect kicks in at high levels of stability, as bribery becomes the more attractive option. Corruption and stability are thus related in a U-shaped pattern. In addition, we show that

our basic propositions continue to hold when we endogenize political stability within the model, taking it to be influenced by the incumbent's choice on public goods provision.

We find that the cross-country evidence supports our main prediction of a U-shaped relation between corruption and political stability, a result that is robust to controlling for many possible alternative determinants of corruption. The discussion of a few country case studies provides further confirmation of the mechanism underlying our theory at the within-country level. Finally, the data reveal a U-shape relation between corruption and the size of government, in accordance with a key corollary of the model: Since the size of government is positively related with stability, corruption therefore stands in a U-shaped relation with the size of government. This finding sheds light on why other studies have been unable to uncover a significant linear relation between these two variables.

There is nevertheless scope for more work to be done on this topic, with the main extensions that we envision concerning the data. There is some debate over whether crosscountry surveys provide adequate measures of corruption. On the one hand, we see the 
robustness of our results as suggesting that such measures do contain useful information beyond their oft-noted correlation with GDP per capita: It is hard to believe that such nonlinear relations could be attributed to random noise. On the other hand, more precise data is clearly desirable. In particular, it would be useful to test our theory against more micro-level data on corruption that can allow us to distinguish between the two kinds of corruption that we identify here.

On the theory side, it would be interesting to use this model as a springboard for further explorations on the nature of the relations between stability and corruption. This could mean a more detailed look at the determinants of stability (for example, political competition, voters' behavior, and the use of patronage networks), or a closer focus on the nature of the corrupt relationship between the incumbent and the private sector. These are all in our plans for future research.

\section{References}

Ades, Alberto, and Rafael Di Tella, (1999), "Rents, Competition, and Corruption," American Economic Review 89: 982-993.

Alesina, Alberto, and George-Marios Angeletos, (2004), "Corruption, Inequality, and Fairness," Harvard University, mimeo.

Alesina, Alberto, Arnaud Devleeschauwer, William Easterly, Sergio Kurlat, and Romain Wacziarg, (2003), "Fractionalization," Journal of Economic Growth 8: 155-194.

Alesina, Alberto, Reza Baqir, and William Easterly, (1999), "Public Goods and Ethnic Divisions," Quarterly Journal of Economics 114: 1243-1284.

Alesina, Alberto, Sule Özler, Nouriel Roubini, and Philip Swagel, (1996), Journal of Economic Growth 2: 189-213.

Alesina, Alberto, and Roberto Perotti, (1996), "Income Distribution, Political Instability and Investment," European Economic Review 40: 1202-1229.

Bardhan, Pranab, (1997), "Corruption and Development: A Review of Issues," Journal of Economic Literature 35: 1320-1346.

Barro, Robert, (1973), "The Control of Politicians: An Economic Model," Public Choice 14: $19-42$.

Beck, Thorsten, George Clarke, Alberto Groff, Philip Keefer, and Patrick Walsh, (2001), "New Tools and New Tests in Comparative Political Economy: The Database of Political Institutions," World Bank Economic Review 15: 165-176. 
Campante, Filipe R., Davin Chor, and Quoc-Anh Do (2004), "Corruption and Instability in a Model with Resurrection," Harvard University, mimeo.

DeLong, J. Bradford, and Andrei Shleifer, (1993), "Princes and Merchants: European City Growth Before the Industrial Revolution," Journal of Law and Economics 36: 671-702.

Dick, Howard, (2001), "Good Governance and the Indonesian economy," in Anthony L. Smith, ed., Gus Dur and the Indonesian Economy, Singapore: Institute of Southeast Asian Studies.

Easterly, William, (2003), "The Political Economy of Growth Without Development: A Case Study of Pakistan," in Dani Rodrik, ed., In Search of Prosperity: Analytical Narratives of Growth, USA: Princeton University Press.

Easterly, William, and Ross Levine, (1997), “Africa's Growth Tragedy: Policies and Ethnic Divisions," Quarterly Journal of Economics 112: 1203-1250.

Easterly, William, and Mirvat Sewadeh, (2001), Global Development Network Growth Database, http://www.worldbank.org/research/growth/GDNdata.htm

Ferejohn, John, (1986), "Incumbent Performance and Electoral Control," Public Choice 30: $5-25$.

Fredriksson, Per G., and Jakob Svensson, (2003), "Political Instability, Corruption and Policy Formation: The Case of Environmental Policy," Journal of Public Economics 87: $1383-1405$.

Geddes, Barbara, and Artur Ribeiro Neto, (1999), "Institutional Sources of Corruption in Brazil," in Keith S. Rosenn and Richard Downes eds., Corruption and Political Reform in Brazil: The Impact of Collor's Impeachment, USA: North-South Center Press at the University of Miami, 21-48.

Glaeser, Edward, and Claudia Goldin, (2004), "Corruption and Reform: An Introduction," NBER Working Paper \#10775, Cambridge, MA: NBER. Forthcoming in Glaeser \& Goldin, eds., Corruption and Reform: Lessons from America's History.

Glaeser, Edward, and Raven Saks, (2004), "Corruption in America," NBER Working Paper \#10821, Cambridge, MA: NBER.

Goodpaster, Gary, (2002), "Reflections on Corruption in Indonesia," in Tim Lindsey \& Howard Dick, eds., Corruption in Asia: Rethinking the Governance Paradigm, Sydney: Federation Press.

Kaufmann, Daniel, Aart Kraay, and Massimo Mastruzzi, (2004), "Governance Matters III: Governance Indicators for 1996-2002," World Bank Policy Research Working Paper 3106.

Knack, Stephen, and Philip Keefer, (1995), "Institutions and Economic Performance: Cross-Country Tests Using Alternative Institutional Measures," Economics 8 Politics 7: 207-227. 
Lambsdorff, Johann, (1999), "Corruption in Empirical Research - A Review," mimeo, http://www.transparency.org/working_papers/lambsdorff/lambsdorff_eresearch.html

Lambsdorff, Johann, (2002), "Background Document to 2002 Corruption Perceptions Index," mimeo, http://www.gwdg.de/ uwvw/downloads/2002_CPI_FD.pdf

La Porta, Rafael, Florencio López-de-Silanes, Cristian Pop-Eleches, and Andrei Shleifer, (2004), "Judicial Checks and Balances," Journal of Political Economy 112: 445-470.

Le, Quan, Guido Mehlkop, Peter Graeff, (2004) "The Mechanism of Corruption and Political Instability," mimeo.

MacIntyre, Andrew, (2003), "Institutions and the Political Economy of Corruption in Developing Countries," mimeo, www.cdi.anu.edu.au/research_publications/research_downloads/StanfordCorruptionpaper.pdf

Mauro, Paolo, (1995), "Corruption and Growth," Quarterly Journal of Economics 110: 681-712.

Mocan, Naci, (2004), "What Determines Corruption? International Evidence from Micro data," NBER Working Paper \#10460, Cambridge, MA: NBER.

Olken, Benjamin, (2004), "Measuring Corruption: Evidence from a Field Experiment in Indonesia," mimeo, Harvard University.

Olson, Mancur, (1991), "Autocracy, Democracy, and Prosperity," in Richard Zeckhauser, ed., Strategy of Choice, Cambridge, MA: MIT Press.

Olson, Mancur, (2000), Power and Prosperity: Outgrowing Communist and Capitalist Dictatorships, USA: Basic Books.

Preston, Julia, and Samuel Dillon, (2004), Opening Mexico: The Making of a Democracy, New York: Farrar, Straus and Giroux.

Rose-Ackerman, Susan, (1999), Corruption and Government: Causes, Consequences, and Reform, USA: Cambridge University Press.

Rosenberg, Tina, (2003), "The Taint of the Greased Palm," The New York Times Magazine, August 10 issue.

Ryan, Orla, (2004), "Kenya Bribes are Growing Bigger," May 17th article, BBC News, http://www.globalpolicy.org/nations/launder/general/2004/0517kenya.htm

Shleifer, Andrei, and Robert Vishny, (1993), "Corruption," Quarterly Journal of Economics 108: 599-617.

Skidmore, Thomas, (1999), "Collor's Downfall in Historical Perspective," in Keith S. Rosenn and Richard Downes eds., Corruption and Political Reform in Brazil: The Impact of Collor's Impeachment, USA: North-South Center Press at the University of Miami, 1-20. 
Souza, Amaury de, (1999), "Collor's Impeachment and Institutional Reform in Brazil," in Keith S. Rosenn and Richard Downes eds., Corruption and Political Reform in Brazil: The Impact of Collor's Impeachment, USA: North-South Center Press at the University of Miami, 87-118.

Svensson, Jakob, (2003), "Who Must Pay Bribes and How Much? Evidence from a Cross Section of Firms," Quarterly Journal of Economics 118: 207-230.

The Economist (1991), "Thieves Fall Out," November 30th issue: 42.

The Economist, (2004), "All Change: The Benefits of Instability", December 11th issue: 48.

The Economist Global Agenda, (2004), "Sickening," July 22nd article, http://www.economist.com/agenda/displayStory.cfm?story_id=2941028

Treisman, Daniel, (2000), "The Causes of Corruption: A Cross-National Study," Journal of Public Economics 76: 399-457.

Van Rijckeghem, Carolina, and Beatrice Weder, (2001), "Bureaucratic Corruption and the Rate of Temptation: Do Wages in the Civil Service Affect Corruption, and by How Much?" Journal of Development Economics 65: 307-31.

Wax, Emily, (2005), "Kenya Is Buffeted By Graft Scandals," The Washington Post, February 12 th article.

Wrong, Michela, (2002), "Growing Political Maturity Erodes Tribalism," The Financial Times, December 28th article: 8. 


\section{Appendix}

\subsection{A Model with a Concave Profit Function from Licensing}

In this Appendix, we consider the case where the private sector's profit function from licensing is concave, exhibiting diminishing returns in the size of the license. In particular, we take $\pi\left(L_{t}, \alpha\right)=\left(1+\alpha^{\frac{1}{1-\gamma}}\right)^{1-\gamma} A_{F} L_{t}^{\gamma}$. This expression can be micro-founded: It is the expected value of a two-period license, where $L_{t}$ is optimally allocated by the firm over periods $t$ and $t+1$, and is exploited in each period using the production function $f(\cdot)=A_{F}(\cdot)^{\gamma}$.

Solving the Bellman equation now yields the following equations (from taking first-order conditions and applying the Envelope Theorem):

$$
\begin{aligned}
1 & =\alpha V^{\prime}\left(K_{1}\right) A \gamma\left(K_{0}-E_{0}-L_{0}\right)^{\gamma-1} \\
\sigma \alpha A_{F}\left(1+\alpha^{\frac{1}{1-\gamma}}\right)^{1-\gamma} \gamma L_{0}^{\gamma-1} & =\alpha V^{\prime}\left(K_{1}\right) A \gamma\left(K_{0}-E_{0}-L_{0}\right)^{\gamma-1} \\
V^{\prime}\left(K_{0}\right) & =\alpha V^{\prime}\left(K_{1}\right) A \gamma\left(K_{0}-E_{0}-L_{0}\right)^{\gamma-1}
\end{aligned}
$$

Assuming an interior solution, the full solution to this problem is given by:

$$
\begin{aligned}
K_{t} & =(A \alpha \gamma)^{\frac{\gamma}{1-\gamma}}, \quad \forall t \geq 1 \\
L_{t} & =\left(\sigma A_{F} \gamma\right)^{\frac{1}{1-\gamma}}\left(1+\alpha^{\frac{1}{1-\gamma}}\right), \quad \forall t \geq 0 \\
E_{0} & =K_{0}-(A \alpha \gamma)^{\frac{1}{1-\gamma}}-\left(\sigma A_{F} \gamma\right)^{\frac{1}{1-\gamma}}\left(1+\alpha^{\frac{1}{1-\gamma}}\right) \\
E_{t} & =A^{\frac{1}{1-\gamma}}(\alpha \gamma)^{\frac{\gamma}{1-\gamma}}-(A \alpha \gamma)^{\frac{1}{1-\gamma}}-\left(\sigma A_{F} \gamma\right)^{\frac{1}{1-\gamma}}\left(1+\alpha^{\frac{1}{1-\gamma}}\right), \quad \forall t \geq 1
\end{aligned}
$$

Notice that the expression for $K_{t}$ is the same as before; the optimal accumulation path of $K_{t}$ is the same as that for a linear profit function. For the interior solution, we need to impose conditions ensuring that $E_{0}$ and $E_{t}$ are non-negative. The first of these (for $E_{0} \geq 0$ ) requires that $K_{0}$ be sufficiently large. The second (for $E_{t} \geq 0$ ) can be re-arranged as follows:

$$
\left(\frac{\sigma A_{F}}{A}\right)^{\frac{1}{1-\gamma}} \leq \frac{\alpha^{\frac{\gamma}{1-\gamma}}(1-\alpha \gamma)}{\gamma\left(1+\alpha^{\frac{1}{1-\gamma}}\right)}
$$

Intuitively, for there to be some embezzlement, licensing cannot be too attractive an option for the incumbent. The condition (13) thus requires that the incumbent's share of revenues 
$(\sigma)$ from licensing and the relative advantage of the private sector technology $\left(A_{F} / A\right)$ not be too large. A quick plot of the right-hand side function in (13) with respect to $\alpha$ for plausible values (eg $\gamma=0.3$ ) shows that it has a very steep positive slope at $\alpha=0$ (where the function also has a zero value), and has a turning point in the interior of $[0,1]$. At $\alpha=1$, the function has a positive value and a negative slope. Thus, for reasonable values of $\frac{\sigma A_{F}}{A}$, one finds that most of the $\alpha$-domain $[0,1]$ easily satisfies (13).

It remains to examine the behavior of corruption, as given by:

$$
\begin{aligned}
& \Gamma_{0}=1-\frac{(A \alpha \gamma)^{\frac{1}{1-\gamma}}}{K_{0}}+\frac{\left(\sigma A_{F}\right)^{\frac{1}{1-\gamma}}}{K_{0}} \gamma^{\frac{\gamma}{1-\gamma}}\left(1+\alpha^{\frac{1}{1-\gamma}}\right)(1-\gamma) \\
& \Gamma_{t}=1-\alpha \gamma+\left(\frac{\sigma A_{F}}{A}\right)^{\frac{1}{1-\gamma}}(1-\gamma)\left(\frac{1+\alpha^{\frac{1}{1-\gamma}}}{\alpha^{\frac{\gamma}{1-\gamma}}}\right), \quad \forall t \geq 1
\end{aligned}
$$

We focus on the comparative statics in steady state (ie for $t \geq 1$ ):

$$
\frac{d \Gamma_{t}}{d \alpha}=-\gamma+\left(\frac{\sigma A_{F}}{A}\right)^{\frac{1}{1-\gamma}}(1-\gamma)\left(1-\frac{\gamma}{1-\gamma} \alpha^{-\frac{1}{1-\gamma}}\right) \begin{cases}>0 & \text { if } \alpha>\alpha^{*} \\ <0 & \text { if } \alpha<\alpha^{*}\end{cases}
$$

where $\alpha^{*}=\left(\frac{1-\gamma}{\gamma}-\left(\frac{A}{\sigma A_{F}}\right)^{\frac{1}{1-\gamma}}\right)^{-(1-\gamma)}$. To ensure that $\alpha^{*} \in[0,1]$, we need the condition that $\left(\frac{\sigma A_{F}}{A}\right)^{\frac{1}{1-\gamma}}>\frac{\gamma}{1-2 \gamma}$, which essentially requires that licensing be attractive enough.

Therefore, for this specification, we also find that corruption is a non-monotonic function of $\alpha$ that can be approximated by a U-shape, driven by the same underlying interplay between the horizon and demand effects. This result generalizes our baseline model to allow for embezzlement and licensing to coexist in equilibrium.

\subsection{Proofs for Model with Endogenous Stability}

\section{Proposition 3}

Proof. Let us restate the optimization program with the introduction of public goods provision:

$$
\begin{aligned}
V\left(K_{0}\right) & =\max _{E_{0}, L_{0}}\left\{E_{0}+\sigma \alpha\left(\zeta, P_{0}\right) A_{F} L_{t}+\alpha\left(\zeta, P_{0}\right) V\left(K_{1}\right)\right\} \\
\text { where } K_{1} & =A\left(K_{0}-E_{0}-L_{0}-P_{0}\right)^{\gamma}
\end{aligned}
$$

First, we will prove that the cleaning-up property holds subject to some general conditions. 
The first order conditions and the Envelope Theorem yield:

$$
\begin{aligned}
1 & =\alpha V^{\prime}\left(K_{1}\right) A \gamma\left(K_{0}-E_{0}-L_{0}-P_{0}\right)^{\gamma-1} \\
\sigma \alpha A_{F} & =\alpha V^{\prime}\left(K_{1}\right) A \gamma\left(K_{0}-E_{0}-L_{0}-P_{0}\right)^{\gamma-1} \\
\alpha^{\prime}\left(P_{0}\right)\left(\sigma A_{F} L_{0}+V\left(K_{1}\right)\right) & =\alpha V^{\prime}\left(K_{1}\right) A \gamma\left(K_{0}-E_{0}-L_{0}-P_{0}\right)^{\gamma-1} \\
V^{\prime}\left(K_{0}\right) & =\alpha V^{\prime}\left(K_{1}\right) A \gamma\left(K_{0}-E_{0}-L_{0}-P_{0}\right)^{\gamma-1}
\end{aligned}
$$

However, only one of equations (15) and (16) can be satisfied at the same time (except in a knife-edge case). Suppose that (15) binds, which means that there is no licensing. We deduce from (15) and (18) that $V^{\prime}(K)=1, \forall K \geq K_{t}$. From (15), it follows that $K_{0}-E_{0}-P_{0}=(A \alpha \gamma)^{\frac{1}{1-\gamma}}$. Therefore $K_{t}=A^{\frac{1}{1-\gamma}}(\alpha \gamma)^{\frac{\gamma}{1-\gamma}}$, which is exactly the same formula as in the case without public goods provision. The cleaning-up property follows since this formula does not depend on $K_{0}$. Analogously, when (16) binds and there is no embezzlement, (16) and (18) imply that $V^{\prime}(K)=\alpha \sigma A_{F}, \forall K \geq K_{t}$. Then (16) implies that $K_{t}=A^{\frac{1}{1-\gamma}}(\alpha \gamma)^{\frac{\gamma}{1-\gamma}}$, which leads us once again to the cleaning-up property.

Now consider the specific functional form of $\alpha=\min (\zeta, g(P))$. Consider first the case where $\alpha=g(P)$. Here, the optimization program does not depend on intrinsic stability, $\zeta$ :

$$
\begin{aligned}
V\left(K_{0}\right) & =\max \left\{E_{0}+\sigma A_{F} g\left(P_{0}\right) L_{0}+g\left(P_{0}\right) V\left(K_{1}\right)\right\} \\
\text { where } K_{1} & =A\left(K_{0}-E_{0}-L_{0}-P_{0}\right)^{\gamma}
\end{aligned}
$$

Under some mild conditions on $g(P)$ (e.g. $g(P)<1-\epsilon<1$ ), this problem has a solution in $P_{0}$ that we call $\bar{P}\left(K_{0}\right)$; similarly, define $\bar{\zeta}\left(K_{0}\right)=g\left(\bar{P}\left(K_{0}\right)\right)$. Because of the cleaning-up property, $K_{t}(t \geq 1)$ does not depend on $K_{0}$ for sufficiently large $K_{0}$. So $\bar{P}$ and $\bar{\zeta}$ are constant and do not depend on $K_{0}$ from period 1 onwards.

Let $P_{\zeta}$ be the inverse function of $g$, i.e. $g\left(P_{\zeta}\right)=\zeta$. With the cleaning-up property, the program reaches its steady state after just one period. We focus on what happens to steady state value of corruption $\Gamma_{t}$, defined as the government's per period income as a fraction of available resources, by considering two cases:

- If $\zeta \geq \bar{\zeta}$ : The polity displays a high enough level of intrinsic stability, so that $\alpha=$ $\min (\zeta, g(P))=g(P)$. Here, the incumbent essentially solves (19) and thus chooses $P=\bar{P}$. In particular, $\alpha=\bar{\zeta}$, and thus corruption does not depend on $\zeta$ in this case. 
- If $\zeta<\bar{\zeta}$ : Because of the cleaning-up property for $t \geq 1, \bar{\zeta}$ only depends on the exogenous parameters $\sigma, A_{F}, A$ and $\gamma$. As stability cannot reach the level $\bar{\zeta}$, the government chooses to invest $P=P_{\zeta}$, so that $\alpha=\zeta{ }^{30}$ The optimization program now reduces to:

$$
\begin{aligned}
V\left(K_{0}\right) & =\max \left\{E_{0}+\sigma A_{F} \zeta L_{0}+\zeta V\left(K_{1}\right)\right\} \\
\text { where } K_{1} & =A\left(K_{0}-E_{0}-L_{0}-P_{\zeta}\right)^{\gamma}
\end{aligned}
$$

As $P_{\zeta}$ is fixed, we are essentially back to the baseline model with exogenous stability presented in Section 2.1. It follows immediately that $V^{\prime}\left(K_{t}\right)$ is a constant for all $t \geq 0$. We now have two sub-cases:

- If $\sigma A_{F} \zeta<1:^{31}$ The government chooses to embezzle and there is no licensing. The FOCs imply:

$$
\begin{aligned}
\left(K_{0}-E_{0}-P_{\zeta}\right)^{1-\gamma} & =A \zeta \gamma \\
\Rightarrow \quad K_{1}=A\left(K_{0}-E_{0}-P_{\zeta}\right)^{1-\gamma} & =A^{\frac{1}{1-\gamma}}(\zeta \gamma)^{\frac{\gamma}{1-\gamma}} \\
\Rightarrow \quad \Gamma_{t}=\frac{A^{\frac{1}{1-\gamma}}(\zeta \gamma)^{\frac{\gamma}{1-\gamma}}-(A \zeta \gamma)^{\frac{1}{1-\gamma}}-P_{\zeta}}{A^{\frac{1}{1-\gamma}}(\zeta \gamma)^{\frac{\gamma}{1-\gamma}}} & =1-\zeta \gamma-\frac{P_{\zeta}}{A^{\frac{1}{1-\gamma}}(\zeta \gamma)^{\frac{\gamma}{1-\gamma}}}
\end{aligned}
$$

for all $t \geq 1$. Let us call this last expression for corruption $\Gamma_{E}$.

- If $\sigma A_{F} \zeta>1$ : The government chooses to license and there is no embezzlement. The FOCs now imply:

$$
\begin{array}{rlrl} 
& & \zeta \gamma A\left(K_{0}-L_{0}-P_{\zeta}\right)^{\gamma-1} \sigma A_{F} \zeta & =\sigma A_{F} \zeta \\
\Rightarrow & & \zeta \gamma A\left(K_{0}-L_{0}-P_{\zeta}\right)^{\gamma-1} & =1 \\
\Rightarrow & & \left(K_{0}-L_{0}-P_{\zeta}\right)^{1-\gamma} & =\zeta \gamma A \\
\Rightarrow & K_{1} & =A^{\frac{1}{1-\gamma}}(\zeta \gamma)^{\frac{\gamma}{1-\gamma}} \\
\Rightarrow & \Gamma_{t}=\frac{\sigma A_{F} \zeta\left[A^{\frac{1}{1-\gamma}}(\zeta \gamma)^{\frac{\gamma}{1-\gamma}}-(A \zeta \gamma)^{\frac{1}{1-\gamma}}-P_{\zeta}\right]}{A^{\frac{1}{1-\gamma}}(\zeta \gamma)^{\frac{\gamma}{1-\gamma}}} & =\sigma A_{F} \zeta\left[1-\zeta \gamma-\frac{P_{\zeta}}{A^{\frac{1}{1-\gamma}}(\zeta \gamma)^{\frac{\gamma}{1-\gamma}}}\right]
\end{array}
$$

for all $t \geq 1$. Let us call this last expression $\Gamma_{E}$

\footnotetext{
${ }^{30}$ The value function is concave in $P$ if $g(P)$ is concave, and therefore has a unique maximum at $\bar{P}$. The value function is thus increasing in the interval $[0, \bar{P}]$.

${ }^{31}$ We assume that $\frac{1}{\sigma A_{F}}<\bar{\zeta}$.
} 
We can now show that with certain conditions on the stability function $g(P)$, the steady state level of corruption has a generalized U-shape, or a "root-shape" $\sqrt{ }$, with respect to $\zeta$. That is, when the level of intrinsic stability $\zeta$ goes up, steady state corruption first declines, then increases, before stabilizing at a constant level. To establish this, we need to show that $\Gamma_{E}$ is decreasing while $\Gamma_{L}$ is increasing in $\zeta$.

We limit ourselves to the class of increasing, concave functions $g(P)=(c P)^{\rho}$ with parameters $c$ and $\rho$. Then $P_{\zeta}=\left(\frac{\zeta}{c}\right)^{\frac{1}{\rho}}$ and:

$$
\Gamma_{E}=1-\zeta \gamma-\frac{\zeta^{\frac{1}{\rho}-\frac{\gamma}{1-\gamma}}}{c^{\frac{1}{\rho}} A^{\frac{1}{1-\gamma}} \gamma^{\frac{\gamma}{1-\gamma}}} \equiv 1-\zeta \gamma-B \zeta^{\frac{1}{\rho}-\frac{\gamma}{1-\gamma}}
$$

A sufficient condition for $\Gamma_{E}$ to be decreasing in $\zeta$ is thus $\frac{1}{\rho} \geq \frac{\gamma}{1-\gamma}$, or equivalently:

$$
\rho \leq \frac{1-\gamma}{\gamma}
$$

Intuitively, for the horizon effect to exist on this "decreasing arm" of the "root-shape", public goods provision must display sufficient diminishing returns so that there is not too much of an incentive to increase its provision and invest in future stability. (Note that the condition $\gamma<\frac{1}{2}$ ensures that $\rho<1$.)

On the other hand, we have $\frac{\partial}{\partial \zeta} \Gamma_{L} \geq 0$ if and only if:

$$
\frac{1-2 \zeta \gamma}{\zeta^{\frac{1}{\rho}-\frac{\gamma}{1-\gamma}-1}\left(\zeta+\frac{1}{\rho}-\frac{\gamma}{1-\gamma}\right)} \geq B
$$

This last inequality, combined with (21), generates the generalized U-shape of corruption. It is worthwhile stressing that these conditions are in fact quite reasonable. To illustrate, suppose that $\rho=\frac{1-\gamma}{\gamma}$. (22) then simplifies to $1-2 \zeta \gamma \geq B$, which is satisfied when $B$ is sufficiently small (or equivalently, when $c$ and $A$ are large enough), bearing in mind that $\gamma<\frac{1}{2}$. In words, we get the "increasing arm" of the "root-shape" when the economy's accumulation technology and that for public goods provision are sufficiently efficient; there is thus an incentive not to embezzle everything immediately, and some resources are available for licensing instead. 
Table 1

\section{Corruption and Government Majority - Cross-Country Evidence}

\begin{tabular}{|c|c|c|c|c|c|c|c|c|}
\hline & $(1)$ & $(2)$ & (3) & $(4)$ & $(5)$ & (6) & $\begin{array}{c}(7) \\
\mathrm{DEM} \geq 5\end{array}$ & $\begin{array}{c}(8) \\
\text { LIEC } \geq 5\end{array}$ \\
\hline (Government Majority) $^{2}$ & $\begin{array}{c}4.549^{* * *} \\
(1.435)\end{array}$ & $\begin{array}{c}2.944^{* * *} \\
(0.808)\end{array}$ & $\begin{array}{c}1.919^{* * *} \\
(0.648)\end{array}$ & $\begin{array}{c}1.736^{* * *} \\
(0.640)\end{array}$ & $\begin{array}{c}1.393^{* *} \\
(0.654)\end{array}$ & $\begin{array}{c}1.108^{* *} \\
(0.430)\end{array}$ & $\begin{array}{c}1.927^{* * *} \\
(0.679)\end{array}$ & $\begin{array}{c}1.308^{* * *} \\
(0.478)\end{array}$ \\
\hline $\log (\mathrm{WDI})$ & - & $\begin{array}{c}-0.742^{* * *} \\
(0.051)\end{array}$ & $\begin{array}{c}-0.630^{* * *} \\
(0.066)\end{array}$ & $\begin{array}{c}-0.602^{* * *} \\
(0.073)\end{array}$ & $\begin{array}{c}-0.603^{* * *} \\
(0.061)\end{array}$ & $\begin{array}{c}-0.196^{* * *} \\
(0.046)\end{array}$ & $\begin{array}{c}-0.226^{* * *} \\
(0.056)\end{array}$ & $\begin{array}{c}-0.219^{* * *} \\
(0.043)\end{array}$ \\
\hline ELF Ethnic & - & - & - & $\begin{array}{l}0.403^{*} \\
(0.220)\end{array}$ & $\begin{array}{c}0.306 \\
(0.222)\end{array}$ & $\begin{array}{c}0.051 \\
(0.111)\end{array}$ & $\begin{array}{l}-0.084 \\
(0.118)\end{array}$ & $\begin{array}{c}0.037 \\
(0.113)\end{array}$ \\
\hline British Legal Origin & - & - & - & $\begin{array}{c}-0.188^{*} \\
(0.113)\end{array}$ & $\begin{array}{l}-0.148 \\
(0.112)\end{array}$ & $\begin{array}{l}-0.014 \\
(0.058)\end{array}$ & $\begin{array}{l}-0.007 \\
(0.069)\end{array}$ & $\begin{array}{l}-0.056 \\
(0.061)\end{array}$ \\
\hline Oil Exporter Dummy & - & - & - & - & $\begin{array}{c}0.458^{* *} \\
(0.213)\end{array}$ & $\begin{array}{c}0.010 \\
(0.063)\end{array}$ & $\begin{array}{l}0.138^{*} \\
(0.080)\end{array}$ & $\begin{array}{c}0.037 \\
(0.060)\end{array}$ \\
\hline Imports / GDP & - & - & - & - & $\begin{array}{l}0.000 \\
(0.002)\end{array}$ & $\begin{array}{c}0.001 \\
(0.001)\end{array}$ & $\begin{array}{l}0.002^{*} \\
(0.001)\end{array}$ & $\begin{array}{c}0.001 \\
(0.001)\end{array}$ \\
\hline Turning point (for Majority) & 0.58 & 0.70 & 0.67 & 0.67 & 0.69 & 0.69 & 0.64 & 0.66 \\
\hline Probability $\in[0,1]$ & 0.996 & 0.997 & 0.991 & 0.984 & 0.951 & 0.982 & 0.992 & 0.989 \\
\hline Region fixed effects & No & No & Yes & Yes & Yes & Yes & Yes & Yes \\
\hline$R^{2}$ & 0.08 & 0.68 & 0.79 & 0.80 & 0.82 & 0.94 & 0.94 & 0.94 \\
\hline Number of observations & 384 & 366 & 366 & 348 & 327 & 218 & 150 & 202 \\
\hline Number of countries & 128 & 122 & 122 & 116 & 109 & 109 & 75 & 101 \\
\hline
\end{tabular}

Notes: Robust standard errors, clustered by country, in parentheses. $* * *, * *$ and $*$ denote significance at the $1 \%, 5 \%$ and $10 \%$ levels respectively. Only countries that provided all three years

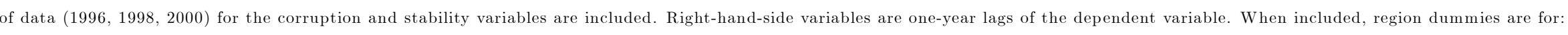
East Asia and the Pacific; East Europe and Central Asia; Middle East and North America; South Asia; West Europe; North America; Sub-Saharan Africa; Latin America and the Caribbean.

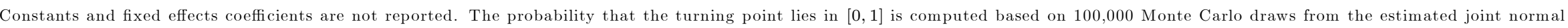
distribution of the coefficients of Stability and Stability squared. 
Table 2

Corruption and Opposition Fractionalization - Cross-Country Evidence

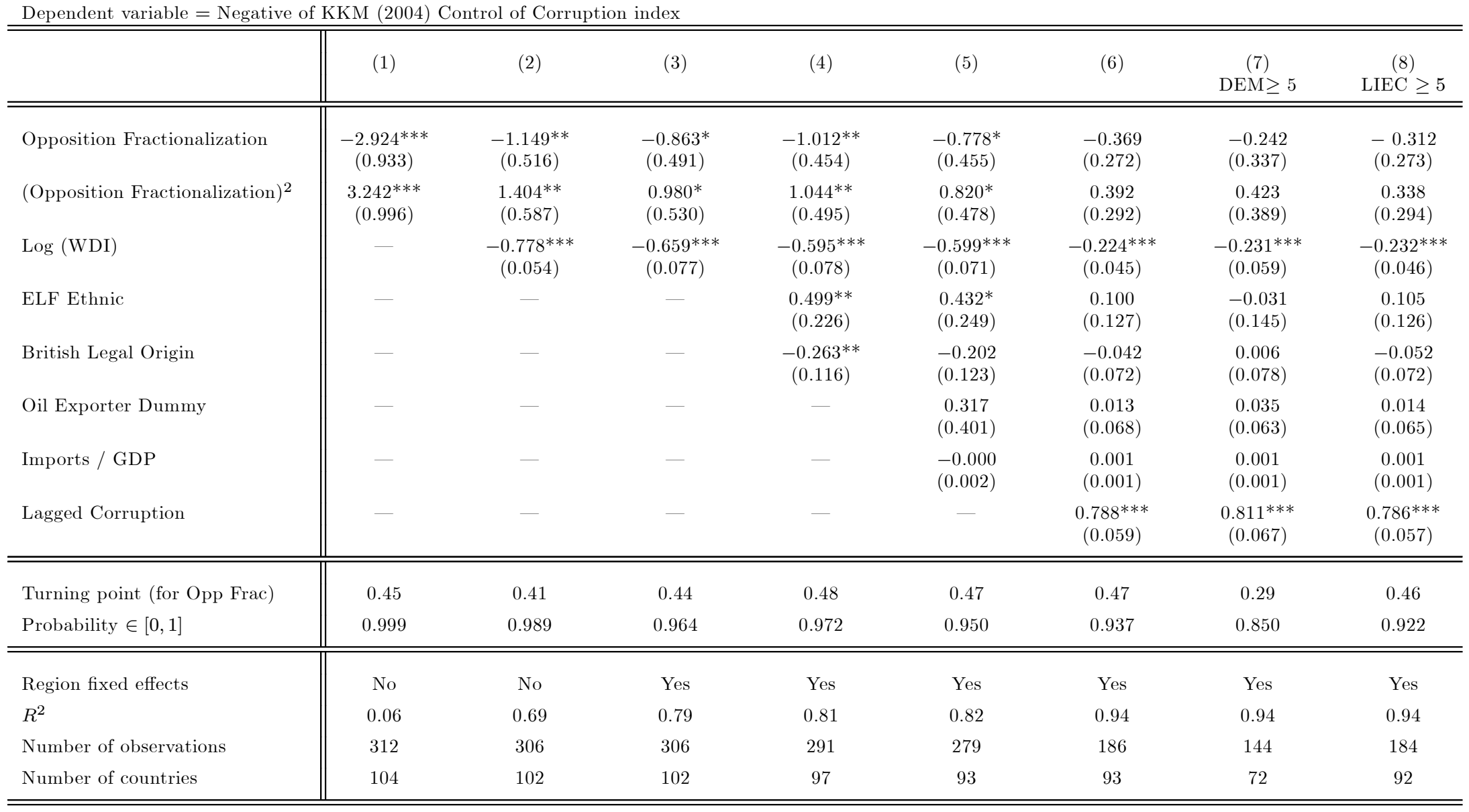

Notes: See Table 1. Robust standard errors, clustered by country, in parentheses. ${ }^{* * *},{ }^{* *}$ and $*$ denote significance at the $1 \%, 5 \%$ and $10 \%$ levels respectively. 
Table 3

Corruption and the Size of Government - Cross-Country Evidence

\begin{tabular}{|c|c|c|c|c|}
\hline \multirow[t]{2}{*}{ Estimation by OLS } & \multicolumn{4}{|c|}{ Total Expenditure / GDP } \\
\hline & $(1)$ & $(2)$ & $(3)$ & $(4)$ \\
\hline Size of Govt & $\begin{array}{c}-4.704^{* * *} \\
(1.044)\end{array}$ & $\begin{array}{c}-12.964^{* * *} \\
(4.401)\end{array}$ & $\begin{array}{l}-6.503 \\
(4.985)\end{array}$ & $\begin{array}{c}-10.933^{* *} \\
(4.595)\end{array}$ \\
\hline$(\text { Size of Govt })^{2}$ & - & $\begin{array}{c}13.641^{*} \\
(7.314)\end{array}$ & $\begin{array}{l}10.153 \\
(7.578)\end{array}$ & $\begin{array}{c}15.093^{* *} \\
(7.155)\end{array}$ \\
\hline $\log (\mathrm{WDI})$ & - & - & $\begin{array}{c}-0.900^{* * *} \\
(0.112)\end{array}$ & $\begin{array}{c}-0.811^{* * *} \\
(0.109)\end{array}$ \\
\hline Turning point (for Size of Govt) & - & 0.475 & 0.320 & 0.362 \\
\hline Probability $\in[0,1]$ & - & 0.918 & 0.965 & 0.983 \\
\hline Region fixed effects & No & No & No & Yes \\
\hline$R^{2}$ & 0.24 & 0.22 & 0.68 & 0.80 \\
\hline Number of observations & 108 & 108 & 106 & 106 \\
\hline Number of countries & 54 & 54 & 53 & 53 \\
\hline
\end{tabular}

Notes: See Notes to Table 1. Robust standard errors, clustered by country, in parentheses. Countries included are those from the Table 1 sample for which government financial data for both 1996 and 1998 are also available. 
Appendix Table 1

Corruption and Political Stability - Additional Cross-Country Evidence

\begin{tabular}{|c|c|c|c|c|c|c|c|c|c|c|}
\hline \multirow[t]{2}{*}{ Estimation by OLS } & \multicolumn{5}{|c|}{ Government share of seats in legislature ("Majority") } & \multicolumn{5}{|c|}{ Fractionalization Index of Opposition ("FracOpp") } \\
\hline & $(1)$ & $(2)$ & $(3)$ & (4) & $(5)$ & $(6)$ & $(7)$ & $(8)$ & $(9)$ & $(10)$ \\
\hline Stability & $\begin{array}{c}-19.960 * * * \\
(7.267)\end{array}$ & $\begin{array}{c}-8.088^{* *} \\
(3.855)\end{array}$ & $\begin{array}{l}-2.721 \\
(3.034)\end{array}$ & $\begin{array}{c}-7.729^{* *} \\
(3.311)\end{array}$ & $\begin{array}{l}-2.276 \\
(3.329)\end{array}$ & $\begin{array}{l}-4.540 \\
(2.973)\end{array}$ & $\begin{array}{l}-0.788 \\
(1.948)\end{array}$ & $\begin{array}{l}-2.064 \\
(1.729)\end{array}$ & $\begin{array}{l}-1.425 \\
(2.561)\end{array}$ & $\begin{array}{l}-2.064 \\
(1.729)\end{array}$ \\
\hline$(\text { Stability })^{2}$ & $\begin{array}{c}16.185^{* * *} \\
(5.608)\end{array}$ & $\begin{array}{c}4.803 \\
(3.125)\end{array}$ & $\begin{array}{c}1.710 \\
(2.633)\end{array}$ & $\begin{array}{c}6.970^{* *} \\
(2.819)\end{array}$ & $\begin{array}{c}1.268 \\
(2.966)\end{array}$ & $\begin{array}{l}5.789^{*} \\
(3.006)\end{array}$ & $\begin{array}{c}0.922 \\
(2.271)\end{array}$ & $\begin{array}{c}1.447 \\
(1.859)\end{array}$ & $\begin{array}{c}1.307 \\
(2.745)\end{array}$ & $\begin{array}{c}1.447 \\
(1.859)\end{array}$ \\
\hline $\log ($ WDI $)$ & - & $\begin{array}{c}-1.838^{* * *} \\
(0.213)\end{array}$ & $\begin{array}{c}-1.623^{* * *} \\
(0.257)\end{array}$ & $\begin{array}{c}-1.451^{* * *} \\
(0.354)\end{array}$ & $\begin{array}{c}-1.600^{* * *} \\
(0.257)\end{array}$ & - & $\begin{array}{c}-1.785^{* * *} \\
(0.210)\end{array}$ & $\begin{array}{c}-1.677^{* * *} \\
(0.263)\end{array}$ & $\begin{array}{c}-1.504^{* * *} \\
(0.388)\end{array}$ & $\begin{array}{c}-1.677^{* * *} \\
(0.263)\end{array}$ \\
\hline Turning point (for Stability) & 0.62 & 0.84 & 0.80 & 0.55 & 0.90 & 0.39 & 0.43 & 0.71 & 0.55 & 0.71 \\
\hline Probability $\in[0,1]$ & 0.997 & 0.742 & 0.768 & 0.990 & 0.755 & 0.945 & 0.854 & 0.750 & 0.828 & 0.750 \\
\hline Region fixed effects & No & No & Yes & Yes & Yes & No & No & Yes & Yes & Yes \\
\hline$R^{2}$ & 0.10 & 0.67 & 0.76 & 0.74 & 0.76 & 0.03 & 0.65 & 0.77 & 0.76 & 0.77 \\
\hline Number of observations & 288 & 284 & 284 & 216 & 276 & 260 & 256 & 256 & 204 & 256 \\
\hline Number of countries & 72 & 71 & 71 & 54 & 69 & 65 & 64 & 64 & 51 & 64 \\
\hline Sub-sample & - & - & - & $\mathrm{DEM} \geq 5$ & LIEC $\geq 5$ & - & - & - & $\mathrm{DEM} \geq 5$ & LIEC $\geq 5$ \\
\hline
\end{tabular}

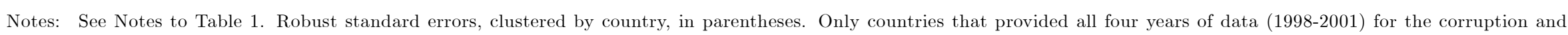
stability variables are included. 


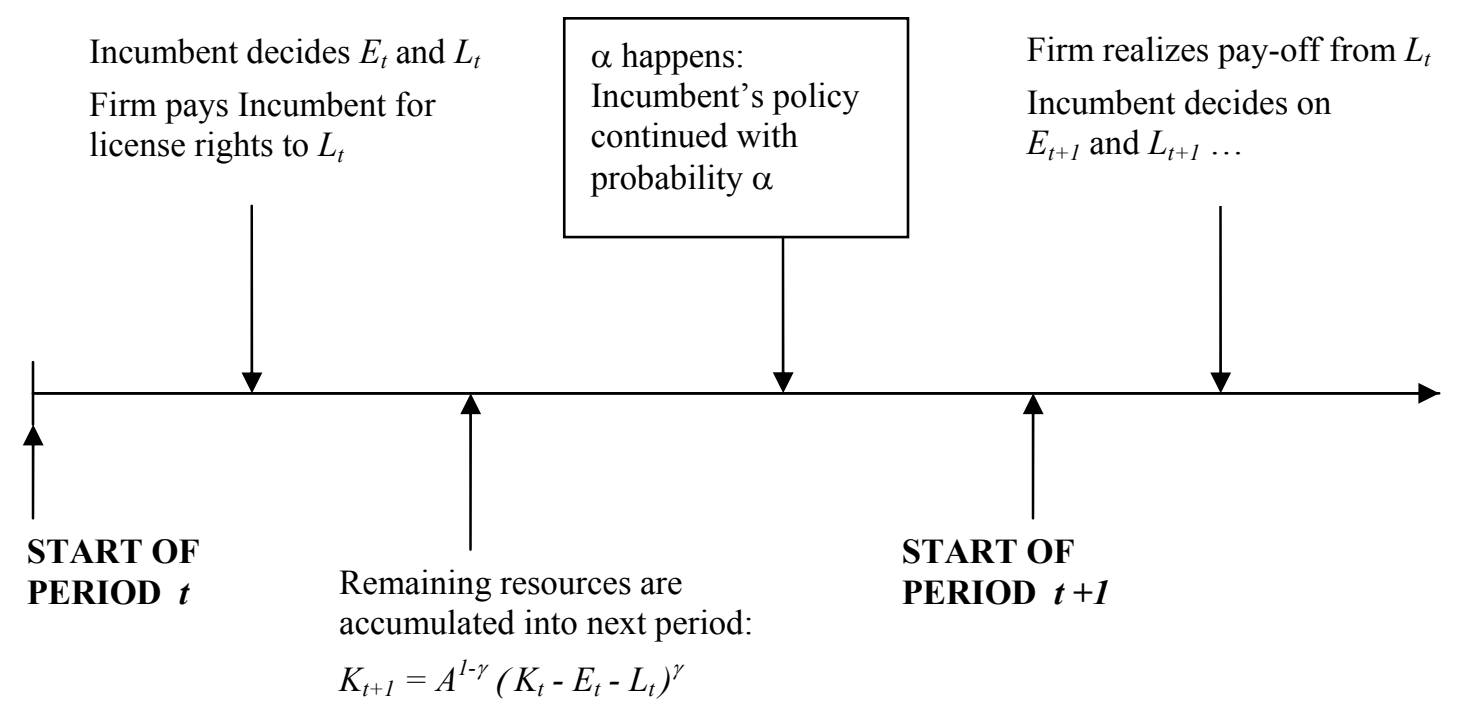

Figure 1: Sequence of events 


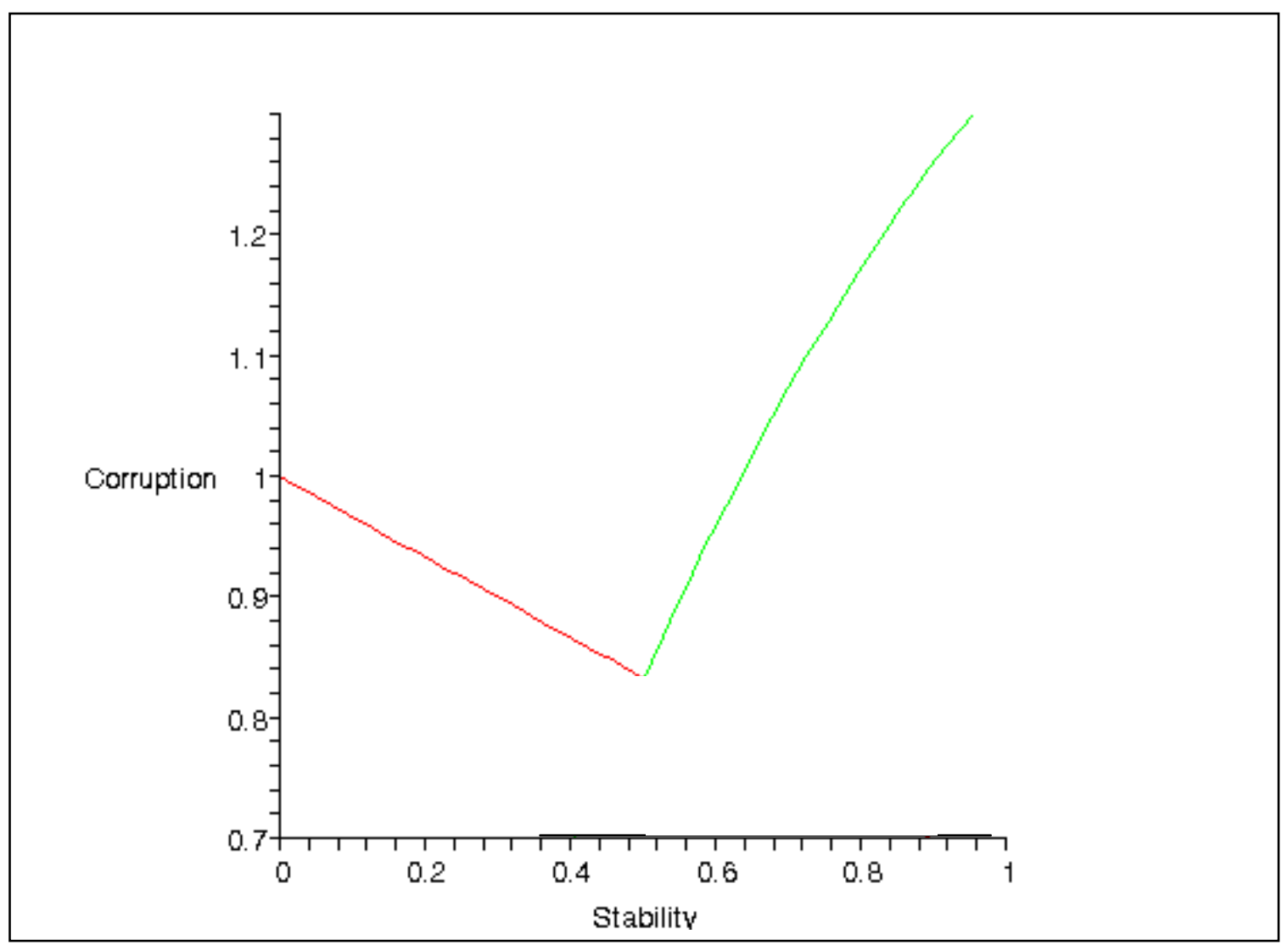

Figure 2 - U-shape.

$\left(\sigma=1 / 2, \gamma=1 / 3, A_{F}=4\right)$ 
Figure 3

The U-shape between Corruption and "Majority"

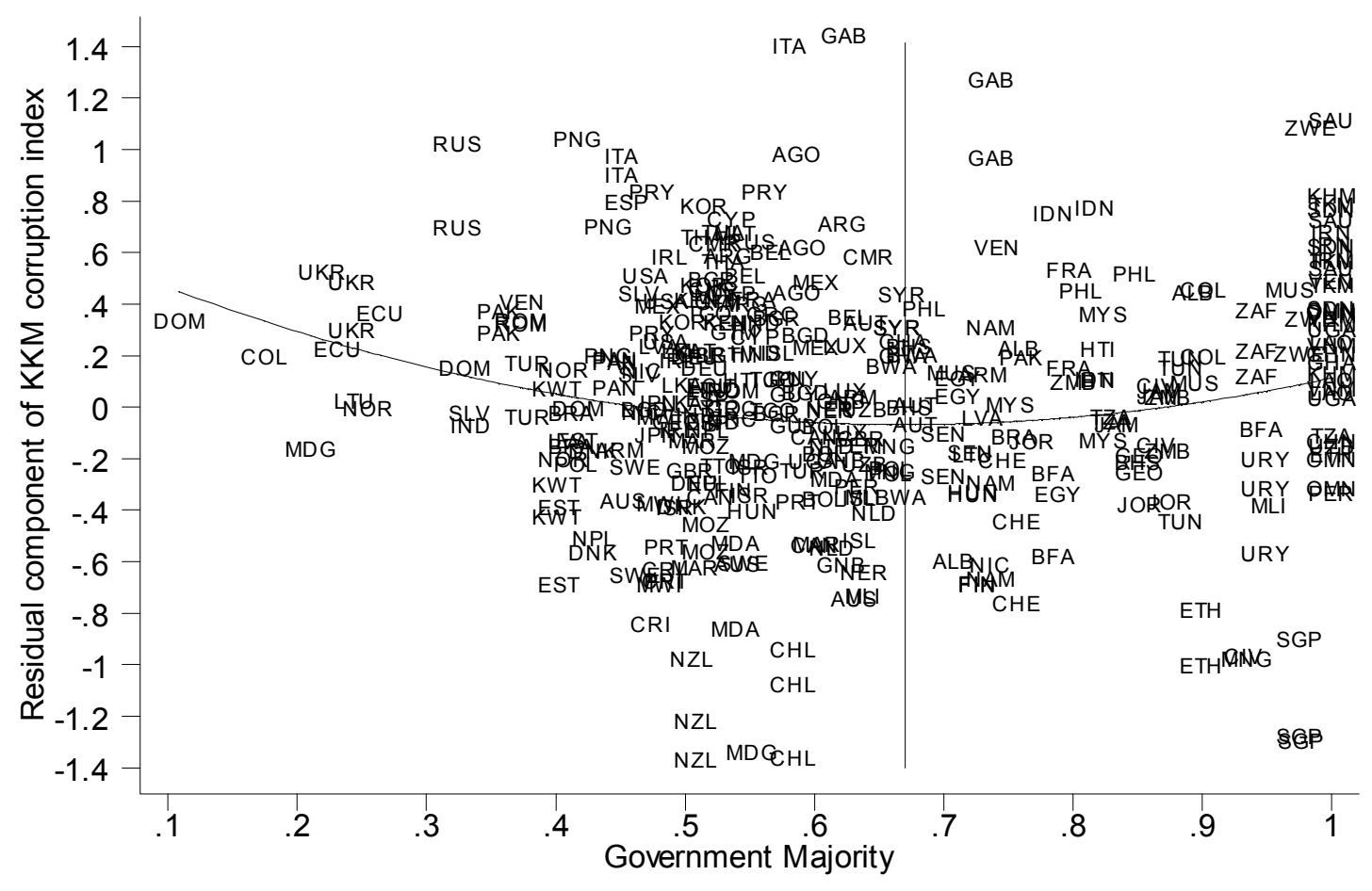

Notes: Residuals are obtained from a regression of the KKM corruption index on log WDI real GDP per capita (one-year lagged), ethnic ELF, a dummy for British legal origin, as well as region and year fixed effects. The U-shape is statistically significant at the $1 \%$ level. The vertical line corresponds to the estimated turning point where government majority $=0.67$. 
Figure 4

\section{The U-shape between Corruption and the Size of Government}

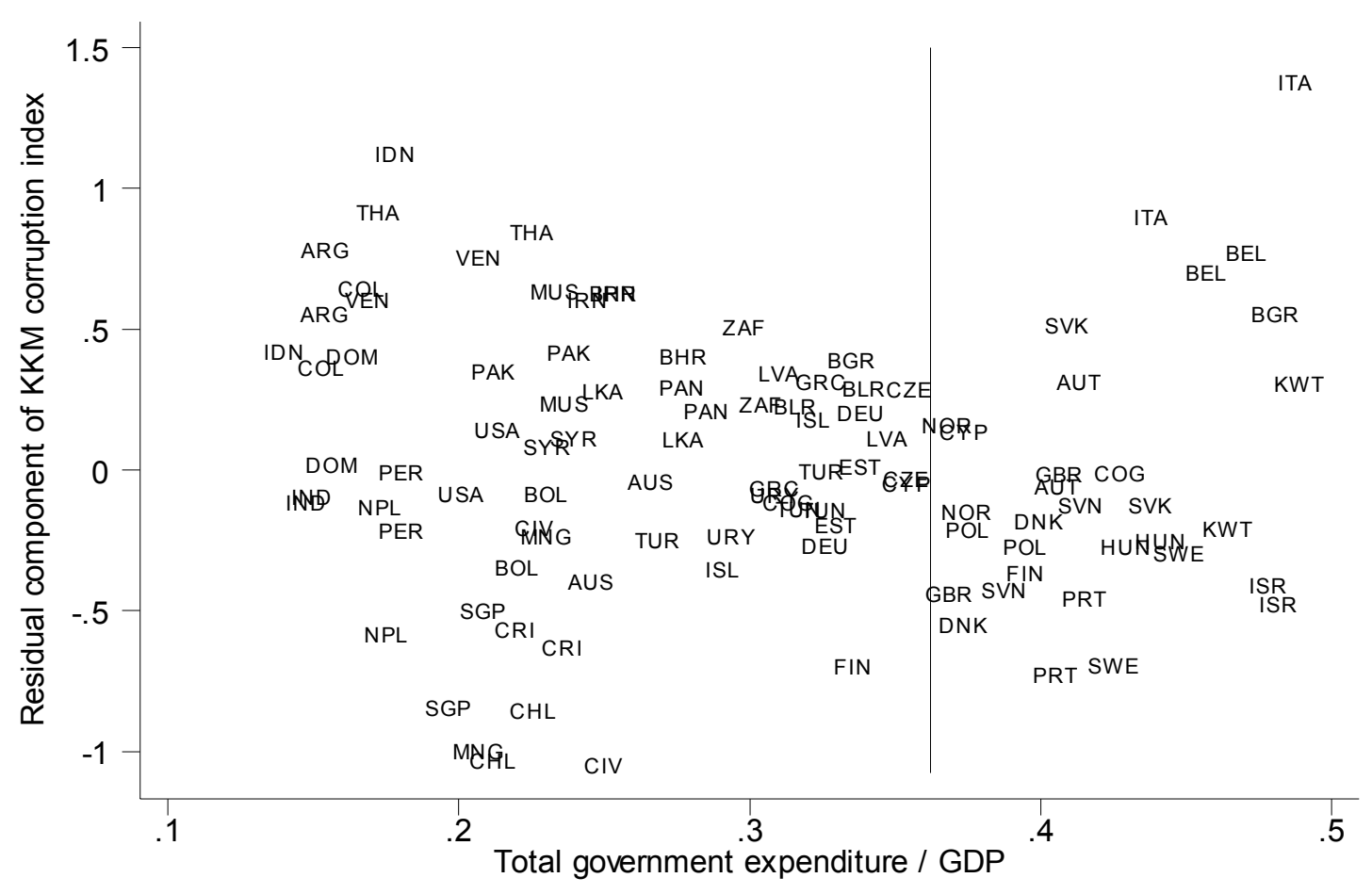

Notes: Residuals are obtained from a regression of the KKM corruption index on log WDI real GDP per capita (one-year lagged) and year fixed effects. The vertical line corresponds to the estimated turning point where government expenditure equals $36.2 \%$ of GDP. 


\section{Data Appendix: List of Sources}

\begin{tabular}{|c|c|}
\hline Data Variable & Description \\
\hline \multicolumn{2}{|l|}{ Corruption } \\
\hline (i) $\mathrm{KKM}$ & $\begin{array}{l}\text { Kaufmann, Kraay and Mastruzzi (2004) aggregate governance indicators. On a scale of }-2.5 \text { to } 2.5 \text {. Measure used is the negative } \\
\text { of KKM's "Control of Corruption" index, which is itself a composite of different agency scores and ratings aggregated by an } \\
\text { unobserved components methodology. Data for 1996, } 1998 \text { and } 2000 \text { used in this paper. Available at } \\
\text { http://www.worldbank.org/wbi/governance/pubs/govmatters3.html }\end{array}$ \\
\hline (ii) $\mathrm{TI}$ & $\begin{array}{l}\text { Transparency International. On a scale of } 0 \text { to } 10 . \text { Measure used is the negative of the TI index. Data for } 1998-2001 \text { used in this } \\
\text { paper, and was obtained from http://www.transparency.org/surveys/index.html\#cpi }\end{array}$ \\
\hline \multicolumn{2}{|l|}{$\underline{\text { Stability }}$} \\
\hline (i) Majority & $\begin{array}{l}\text { From Database of Political Institutions (DPI) by Beck et. al. (2001). Share of seats in the legislature held by members of the } \\
\text { government coalition. Available at http://www.worldbank.org/research/bios/keefer/DPI2000_no_comt_form_macro.xls }\end{array}$ \\
\hline (ii) FracOpp & Ibid. Computed as 1 minus the Herfindahl index of the composition of seats occupied by opposition parties in the legislature. \\
\hline \multicolumn{2}{|l|}{ Other variables } \\
\hline ELF & $\begin{array}{l}\text { Alesina et. al. (2003). Ethno-linguistic fractionalization measures available by ethnicity, language and religion. Measure is } \\
\text { treated as a state variable independent of time. }\end{array}$ \\
\hline Legal Origin & $\begin{array}{l}\text { Dummy variable for British legal origin. Available from the World Bank's Global Development Network Growth Database } \\
\text { (GDNGD) at http://www.worldbank.org/research/growth/GDNdata.htm. }\end{array}$ \\
\hline Oil Exporter & $\begin{array}{l}\text { Dummy variable for oil exporting country. Available from the World Bank's Global Development Network Growth Database } \\
\text { (GDNGD) at http://www.worldbank.org/research/growth/GDNdata.htm. Variable equals one if fuel exports made up more than } \\
50 \% \text { of the total exports of goods and services between 1988-1992. }\end{array}$ \\
\hline Imports / GDP & World Bank World Development Indicators (WDI). \\
\hline
\end{tabular}


Size of Government

Democracy

LIEC

Real GDP per capita

Region dummies
Total government expenditure as a share of GDP. From the GDNGD, based on data originally from the IMF's Government Financial Statistics.

Polity IV democracy score. On a scale of 0 to 10 . Available at http://www.cidcm.umd.edu/inscr/polity/

Legislative Index of Electoral Competitiveness. From Database of Political Institutions (DPI). On a scale of 1 to 7, with 1 indicating no legislature and 7 indicating that the largest party held less than $75 \%$ of seats.

World Bank World Development Indicators (WDI).

Classifications from the GDNGD. Dummy variables are for: East Asia and the Pacific; East Europe and Central Asia; Middle East and North America; South Asia; West Europe; North America; Sub-Saharan Africa; Latin America and the Caribbean. 